\title{
Research Paper \\ The using of Financial Options to in reducing the risk Analysis study in the Dubai Stock Exchange
}

Journal of

\section{TANMIYAT AL- RAFIDAIN}

\section{(TANRA)}

A scientific, quarterly, international, open access, and peer-reviewed journal

Vol. 39, No. 127

Sep., 2020

(C) University of Mosul | College of Administration and Economics, Mosul, Iraq.

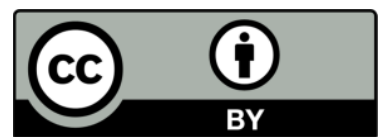

TANRA retain the copyright of published articles, which is released under a "Creative Commons Attribution License for CC-BY-4.0" enabling the unrestricted use, distribution, and reproduction of an article in any medium, provided that the original work is properly cited.

Citation: Sami, Hala (2020).“ The using of financial options to in reducing the risk Analysis study in the Dubai Stock Exchange TANMIYAT AL-RAFIDAIN, 39 (127), 70-102, https://doi.org/10.33899/tanra.20 20.127144 .1023

P-ISSN: 1609-591X e-ISSN: 2664-276X tanmiyat.mosuljournals.com

\section{Hala sami khudier ${ }^{1}$}

University of Mosul / College of Administration \& Economic / Dept. Banking \& Financial Sciences

Corresponding author: Hala sami; Hala_sami@uomosul.edu.iq

DOI: 10.33899/tanra.2020.127144.1023

Article History: Received: 18/5/2020; Revised: 2/6 /2020; Accepted: 20/7/2020; Published: $1 / 9 / 2020$.

\section{Abstract}

The research focused on testing the role of financial options to in reducing the risks faced by investors in the financial markets as a result of the numerous financial problems and crises that ravaged them in recent years. As one of the most important tools that investors use to reduce the risks to which they are exposed, the research has examined in its theoretical part the concept of financial options, the types of options contracts, and their elements and the motives for using financial options to cover risks and pricing strategies for financial options. The Black Shoals model was used in the practical aspect to test the hypothesis of the direct relationship between the use of financial options and risk reduction. The model has been applied in the banking sector in the Dubai Stock Exchange and for the year 2019. For a sample consisting of eleven banks, the research results indicated the power of the Black Shoals model in pricing financial options and reducing losses incurred by investors if that their expectations are not correct, and therefore the research recommends hedging shares against Changes in stock prices by purchasing financial options and using the Black and Scholes model in pricing financial options.

\section{Keywords}

Financial options, types of financial options, black Schwaz model 


\section{ورقة بحثية \\ في ستخدام الخيارات المالية في تخفيض الخطر دراسة تحليلية

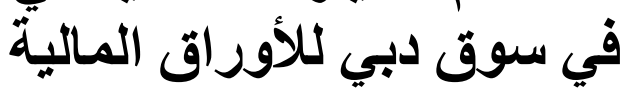

حلا سامي خضير الياسين'

' جامعة الموصل / كلية الادارة والاقتصاد / قسم العلوم المالية والمصرفية

Hala_sami@uomosul.edu.iq ، المؤلف المراسل: حلا سامي خضير الياسين

DOI: 10.33899/tanra.2020.127144.1023

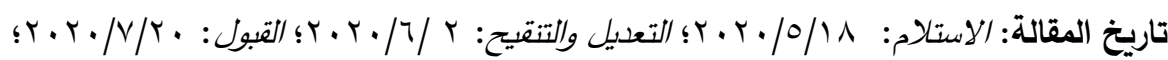

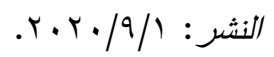

المستخلص

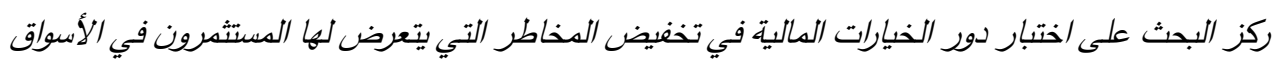

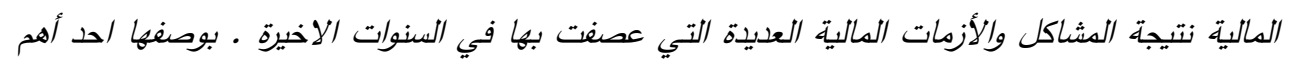

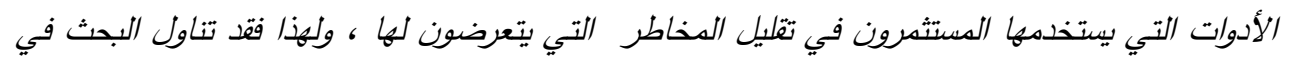

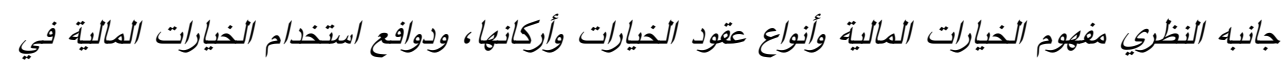

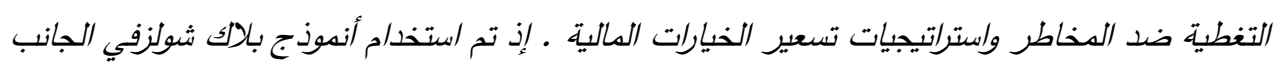

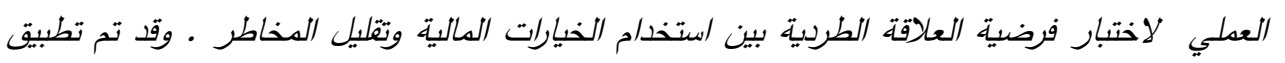

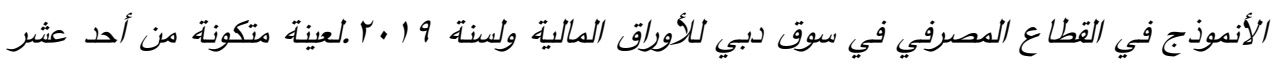

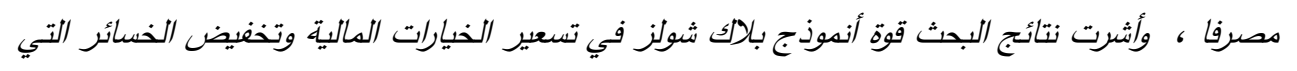

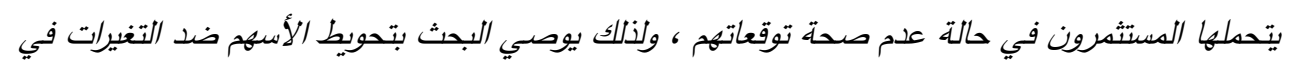
أسعار الأسهم عبر شراء خيارات مالية.

الكلمات المفتاحية

الخيارات المالية ، أنواع الخيارات المالية، نموذج (black Schwaz).

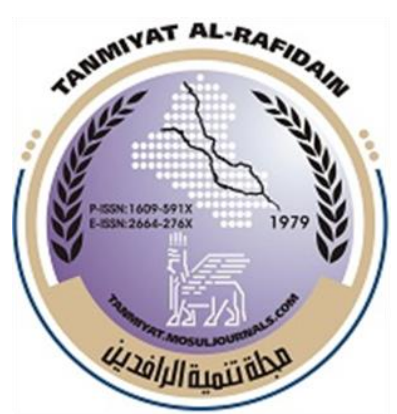

\section{هبلة}

\section{تنسمبية الرافندين}

(TANRA) دولية، مفتوحة الوصول، محكمة.

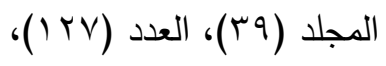

$$
\begin{aligned}
& \text { ايلول .r.r. }
\end{aligned}
$$

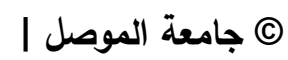
كلية الإدارة والاقتصاد، الموصل، العرله

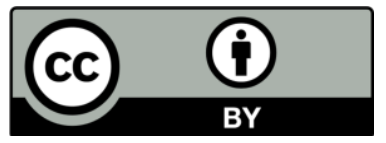

تحتفظ (TANRA) بحقوق الطبع والنشر للمقالات المنشورة، والتي يتم إصدارها بموجب ترخيص لئن ل(Creative Commons Attribution) (CC-BY-4.0) والاستساخ غير المقيد وتوزيع للمقالة في أي وسيط الانيط نقل، بشرط اقتباس العمل الأصلي بشكل صحيح.

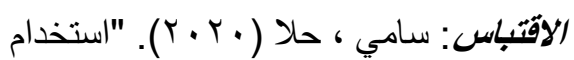

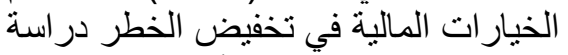

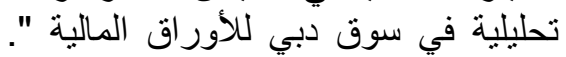

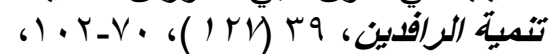
https://doi.org/10.33899/tanra.20 20.127144.1023

P-ISSN: 1609-591X

e-ISSN: 2664-276X

tanmiyat.mosuljournals.com 
واجهت الأسواق المالية الكثير من المخاطر والمشاكل والأزمات المالية المتعددة خلال العقود الاخيرة ومثلت الكثير من الاجراءات التطوعية التي كانت تقوم بتبنيها الأسواق المالية لمواجهة هذه الهزات العنيفة التي كان لها الاثر الكبير في أسعار اسهمها وتقلباتها وتعرضها للخسائر، هذا ما دعا الأسواق المالية

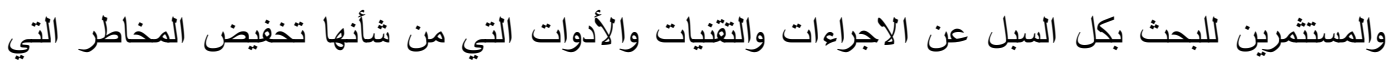
تتعرض لها ، فكانت الخيارات المالية بأنواعها واستراتيجياتها وتتنياتها ونماذجها الدور الفعال والتئ والمؤثر في تقليل المخاطر وتعظيم أرباح الأسهم في الأسواق المالية في ظل المخاطر الكبيرة التي تتعرض لها لها ، إذ ادركت

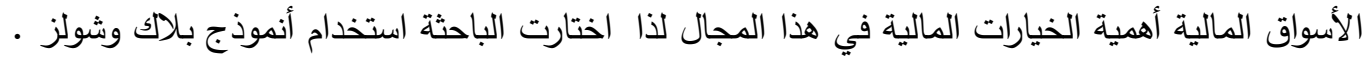

$$
\text { ا- اولا : منهجية البحث: }
$$

من خلال المشاكل والأزمات والمخاطر التي تعرضت لها أسعار الأسهم وظهور الخيارات المالية كأداة لتخفيض تلك المخاطر في الأسواق المالية الحالية والمستقبلية ، هنا يحاول البحث الاجابة على التساؤلات

ا ـ ـ ما ددى مساهمة الخيارات المالية في تخفيض مخاطر أسعار الأسهم ؟

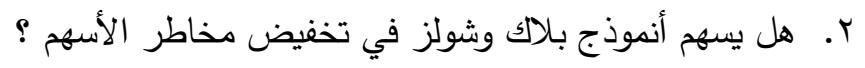

$$
\text { ب- فرضية البحث }
$$

يؤدي استخدام أنموذج بلاك وشولز في تخفيض المخاطر التي تتعرض لها الأسهم في الأسواق

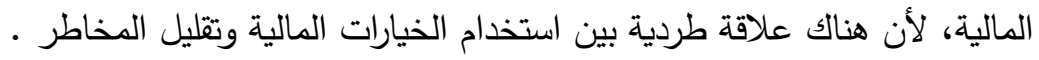

$$
\text { ج -أهية البحث لانث }
$$

تتركز أهمية البحث من الأهمية والدور الفعال الذي تؤديه الخيارات المالية ونماذجها الرياضية في تخفيض والحد من المخاطر التي تتعرض لها أسعار الأسهم في الأسواق المالية .

$$
\text { د -هدف البحث }
$$

يهدف البحث إلى التعرف على مفهوم الخيارات المالية وأنواعها واستراتيجياتها وعلى أنموذج بلاك وشولز في تخفيض مخاطر أسعار الأسهم في الأسواق المالية . هـ -حدود البحث المكانية : سوق دبي للأوراق المالية

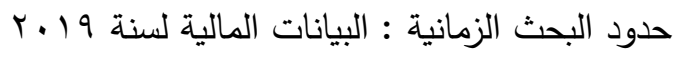


أولا : الأسس النظرية لسوق حقوق الاختيار

1. نشأة أسوق حقوق الاختيار

ازدهرت أسواق حقوق الاختيار في أواخر القرن العشرين نتيجة للاخطار الكبيرة التي واجهها المستثمرون في الأسواق التقليدية انذاك، ولأن الربح والخسارة في الأسواق التقليدية غير محدد ما

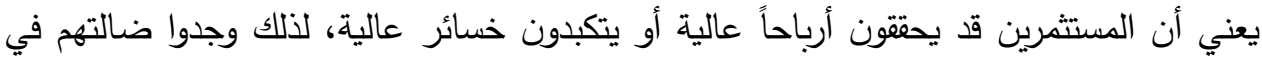
أسواق حقوق الاختيار التي تكون فيها الأرباح غير محدودة والخسائر محدودة ما يسهم في حمايتهم،

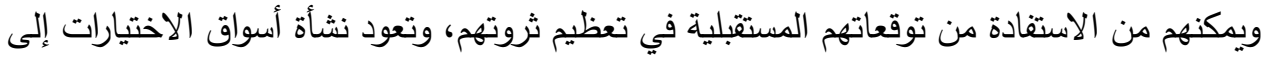
العام ..919 حيث تم إنثاء جمعية الوسطاء والسماسرة لحقوق اختيارات البيع والشراء من قبل مجموعة من الشركات التي تعد الاساس الذي وصلت آلية اسواق حقوق الاختيار من تطور في يومنا هذا، وفي بداية بVI9 ا حصلت تغييرات كبيرة في أسواق حقوق الاختيار من خلال تأسيس

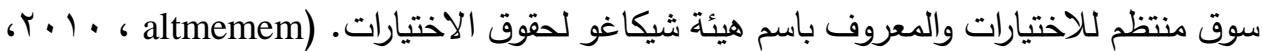

$(r \leq 4$

\section{r. مفهوم حقوق اختيار الثراء}

تمثل حقوق خيارات الثراء عقوداً ثانوية مشتقة من عقود اساسية تتمح حاملها حق الخيار شراء أو بيع عدد من الأوراق المالية بسعر ووقت محددين مقابل مبلغ محدد يسمى مكافأة الخيار ، يتضح

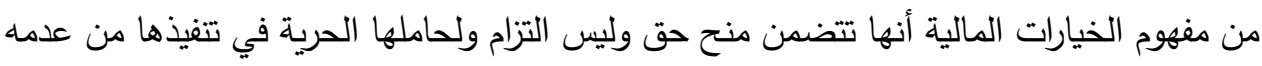
(شراء واعدم شراء الأوراق المالية أو المؤشرات المالية) اعتماداً على تحقق أوعدم تحقق توقعاتهم في

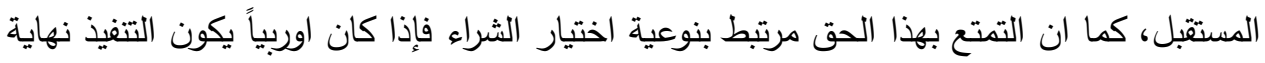
مدة العقد فقط، أي يكون بيد مشتري حق الخيار الشراء فرصة واحدة للتنفيذ أو عدم التتفيذ، أما إإذا

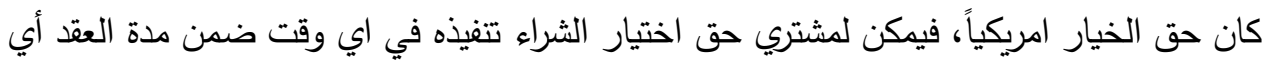

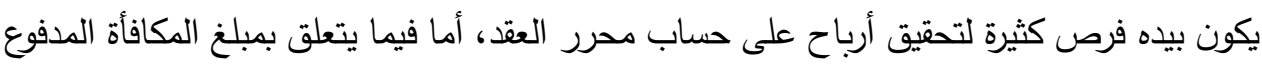

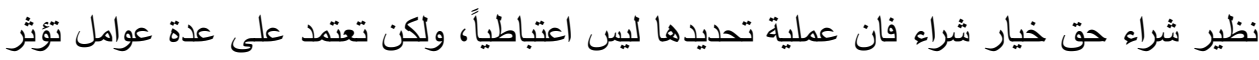

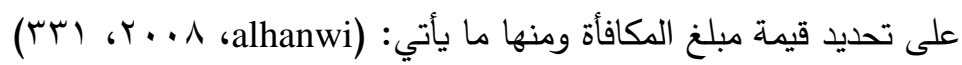

$$
\begin{aligned}
& \text { أ. السعر الحالي للسهم (سعر التنفيذ). } \\
& \text { ب. سعر السهم في تاريخ انتهاء مدة العقد. }
\end{aligned}
$$

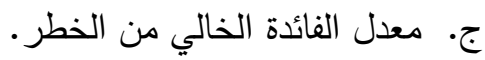

د. الفترة المنقضية بين تاريخ التعاقد وتاريخ الانتهاء في صورة نسبة مئوية من السنة. هـ درجة تقلب في أسعار الأوراق المالية أو المؤشرات المالية.

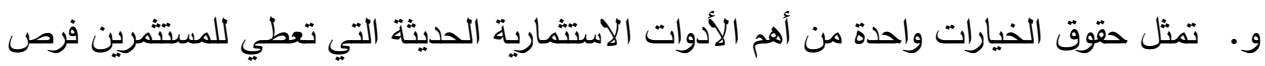

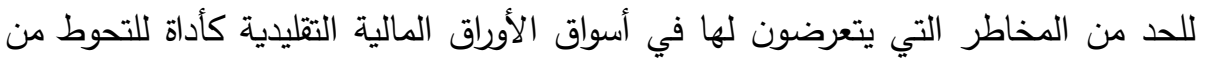


المستقبل الذي يتسم بحالة عدم التاكد والتغيرات الديناميكية المستمرة، أو تستخدم أداة للاسترباح من خلال التوقع الجيد لاتجاهات السوق المستقبلية، ولقد حصلت حقوق الاختيار على تسميتها هذه نظراً لانها تعطي الطرف الاول والمتمثلين بمشتري حقوق الاختيار حقاً اختيارياً وليس إلزامياً في تتفيذ تلك الحقوق اوعدم تنفيذها، وذلك نظير دفعهم مبلغ معين غير قابل للرد لشرائها

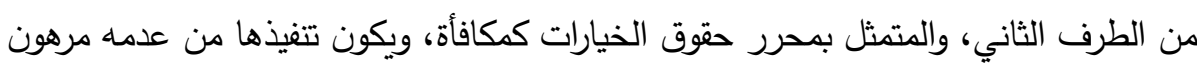

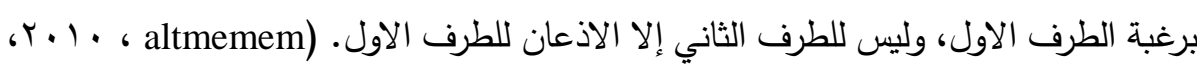

\section{r. عقود الخيارات والمخاطر المالية}

تزايد الاهتمام بإدارة المخاطرة المالية في العقود الاخيرة ، كنتيجة للانفتاح الاقتصادي المتسارع في سوق المال خاصة في القطاعات المصرفية ، وذلك يحدث التحوط من التأثيرات الخارجية

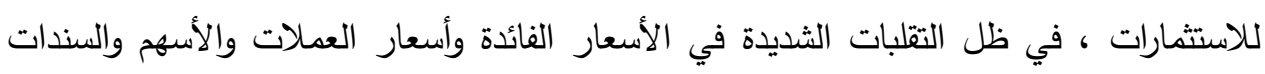
(ro ، r. 19 ، alkndi)

وتعتبر عقود الخيارات أحد أهم المشتقات المالية المستخدمة في إدارة المخاطر المالية ، حيث يعتبر احد أهم إدارة المخاطر في مؤسسات التمويل هو التحوط من خسائر غير مقبولة والتأكد من مراقبة الاخطار خاصة عندما تتجاوز هذه الاخطار سقوفا معينة لتحديد السياسات المالية اللازمة والتي

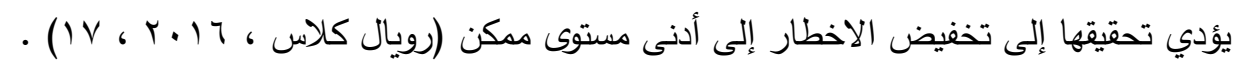

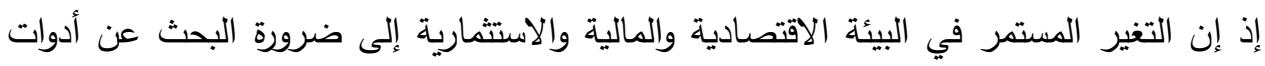

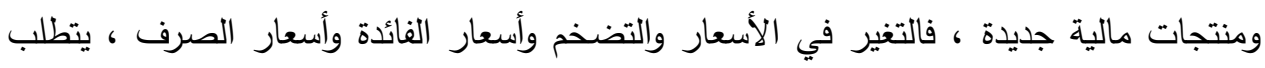

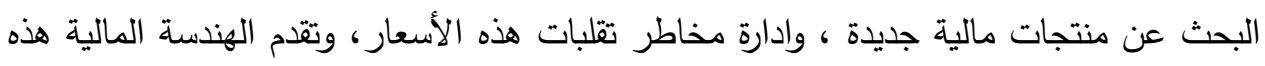

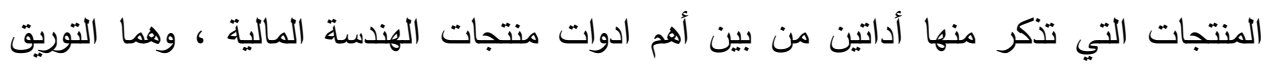

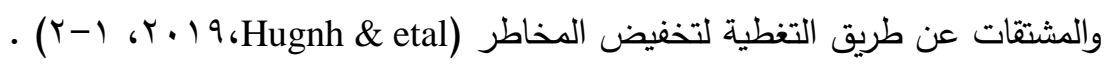
؛ ـ أنواع حقوق الاختيار

هناك أنواع عديدة من عقود حقوق خيارات الشراء وكما يأتي : (Nhuyen, 2016,3-5) أ. حقوق الخيارات الاوربية : وهي حقوق اختيار (لشراء او لبيع) الذي يتم تنفيذها في نهاية تاريخ العقد المحدد لحق الخيارات. ب. حقوق الخيارات الامريكية : وهي حقوق اختيار (لشراء أو لبيع) الذي يتم تتفيذها في، أي خلد الفترة التي تتقضي بين تاريخ إبرام العقد وتاريخ انتهائه. ج. حق خيار الشراء : يتيح هذا الحق للمستثمر (مشتري حق الخيار) شراء عدد من (الأوراق

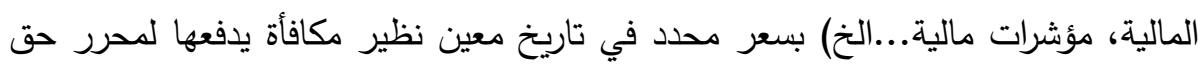
الخيار . n 
د. حق خيار البيع : يتيح هذا الحق للمستثر (مشتري حق الخيار) بيع عدد من الأوراق المالية

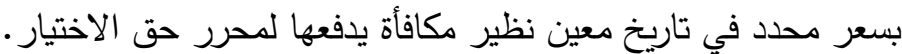
هـ. حق الخيار المغطى : وهو حق اختيار شراء أو بيع يكون فيه احد طرفي العقد مالكاً بالفعل لـ (أوراق مالية، مؤشرات مالية....الخ) التي يتم التعاقد بشأنها.

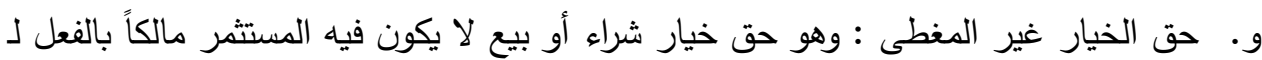
(أوراق مالية، مؤشرات مالية....الخ) التي يتم التعاقد بشأنها.

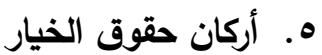

يتضمن عقد حق الخيار الشراء على مجموعة من الاركان وكما يأتي : Global Finance ) اردان

(Swaran,2011,382) (program \& et al., 2008 , 264-266

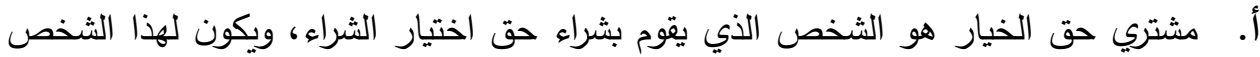
الحق في تتفيذ او عدم تتفيذ الاتفاق نظير مكافأة يدفعها للطرف الثاني، وهو محرر حق الخيار . ب. محرر حق الخيار هو الثخص الذي يقوم بتحرير حق الخيار الثراء (بيعه) لصالح المستثر

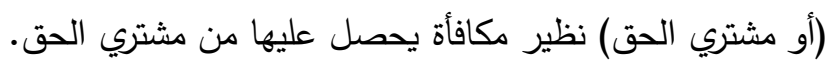

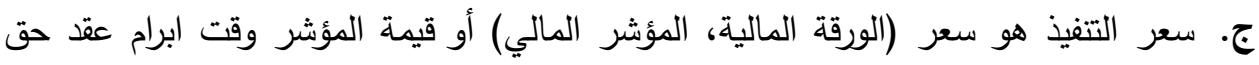

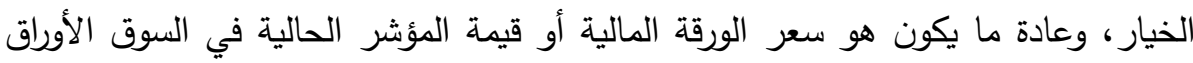

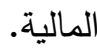

د. السعر السوقي هو سعر (الورقة المالية، المؤشر المالي) في تاريخ انتهاء أو تتفيذ اتفاق عقد حق الخيار. هـ سعر التنفيذ هو تاريخ ابرام عقد حق الخيار وهو عادة أول يوم لسريان الاتفاق.

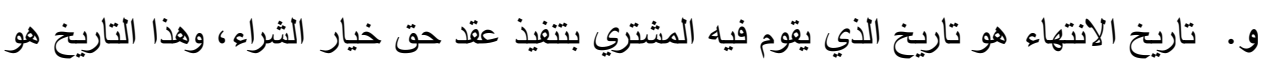
آخر يوم متقق عليه في حالة الخيار الاوربي أو أي يوم يقع بين تاريخ إبرام العقد وتاريخ انتهاء العقد وفقا للخيار الامريكي. ز. المكافأة هو مبلغ متفق عليه يقوم مشتري حق اختيار الثراء بدفعه إلى محرر حق الخيار نظير أن يكون لمشتري الحق في تتفيذ اوعدم تتفيذ الاتفاق.

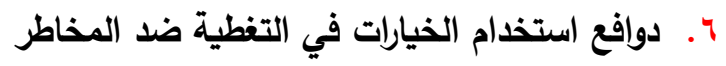

التحوط والتغطية يتبعها المستثر للحد من الخسائر المرتفعة ، دون التقليل بثكل كبير من العوائد

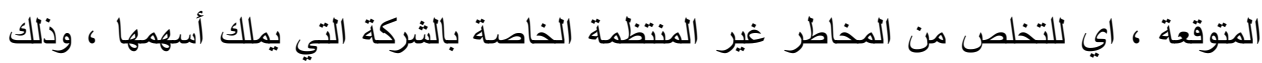

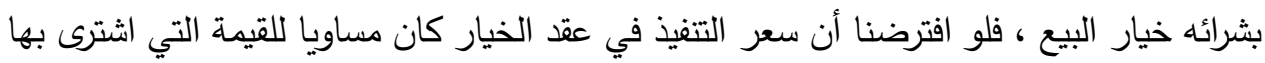
السهم ، وانخفضت القيمة السوقية للسهم عن سعر التتفيذ المتفق عليه ، محددا خسائره بمقدار

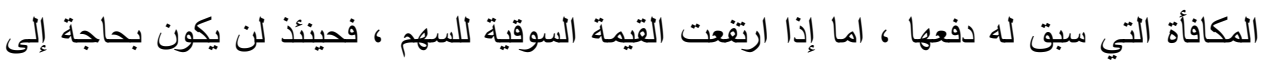


تتفيذ الخيار، وكل ما سيخسره هو قيمة المكافأة التي سيعوضها من الأرباح التي تمثل الفرق بين

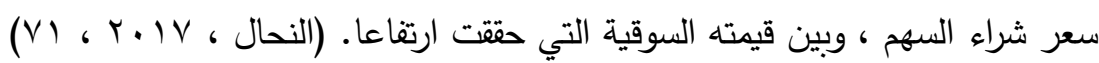
v . استراتيجيات استخدام الخيارات المالية

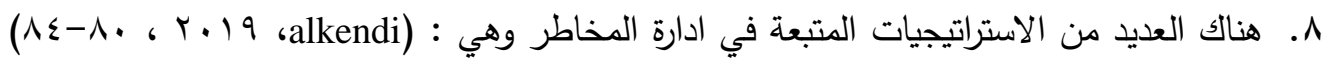

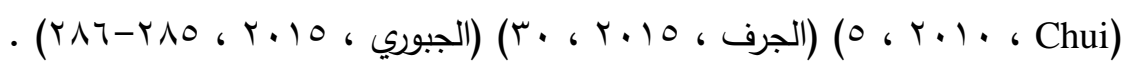

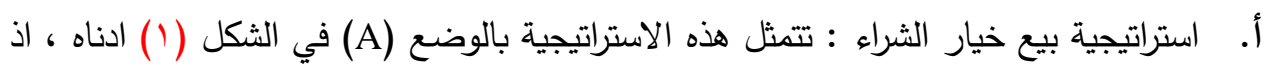
من الممكن استخدام التحوط من قبل محرر الاختيار وفقا لعمل الاستراتيجية فانه يستطيع شراء

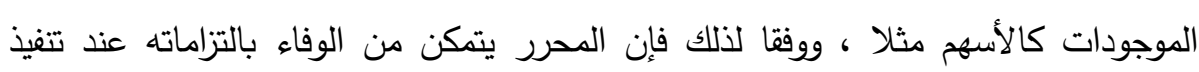

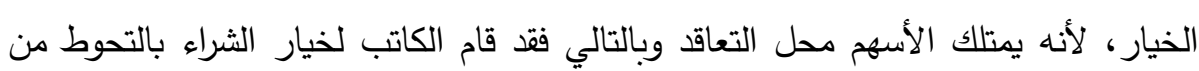

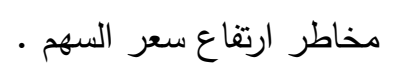
ب. استراتيجية شراء خيار الشراء : تتمثل هذه الاستراتيجية بالوضع (B) في الشكل (1) ) ، وتستخدم

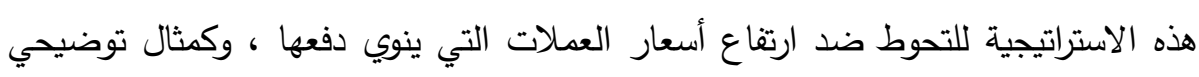

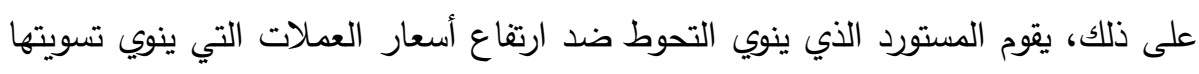

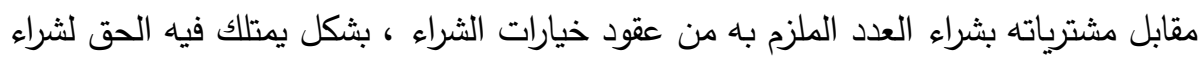

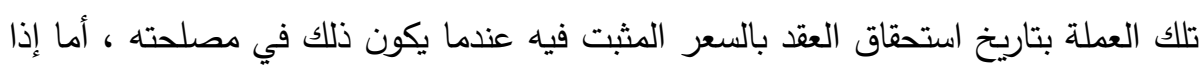

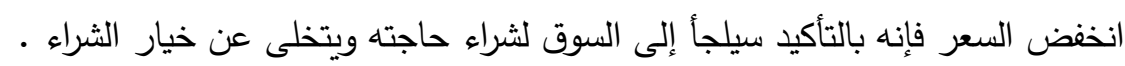

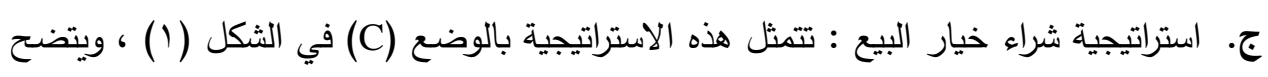
عمل تلك الاستراتيجية اذا كان شخص يمتلك مجموعة من الأسهم ولديه الرغبة في الاحتفاظ

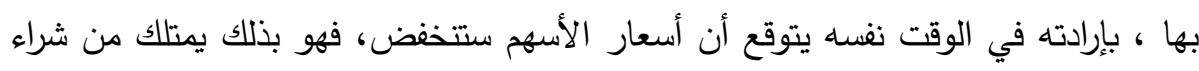

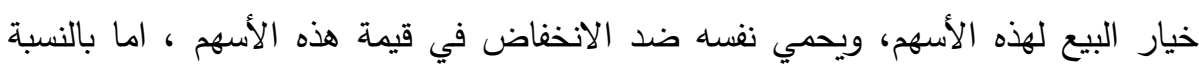

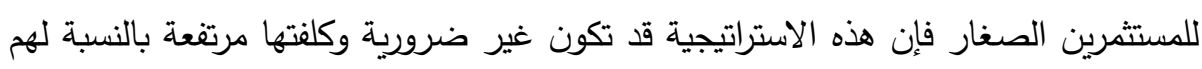

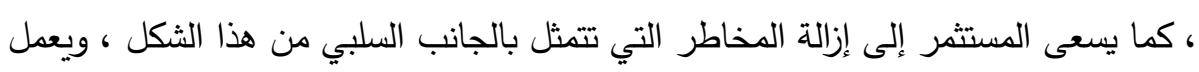

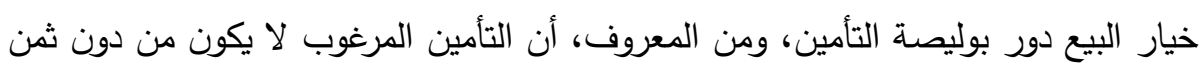
، فتقوم الثركة بدفع ثمن للحصول عليه.

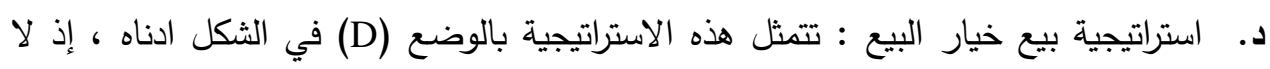

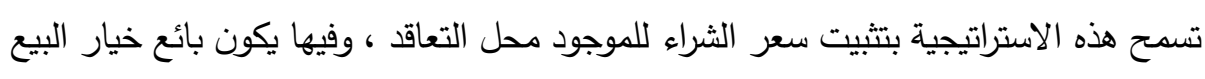

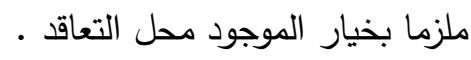
والثكل ادناه يبين استراتيجيات الخيارات المتبعة في إدارة المخاطر لـولئر 


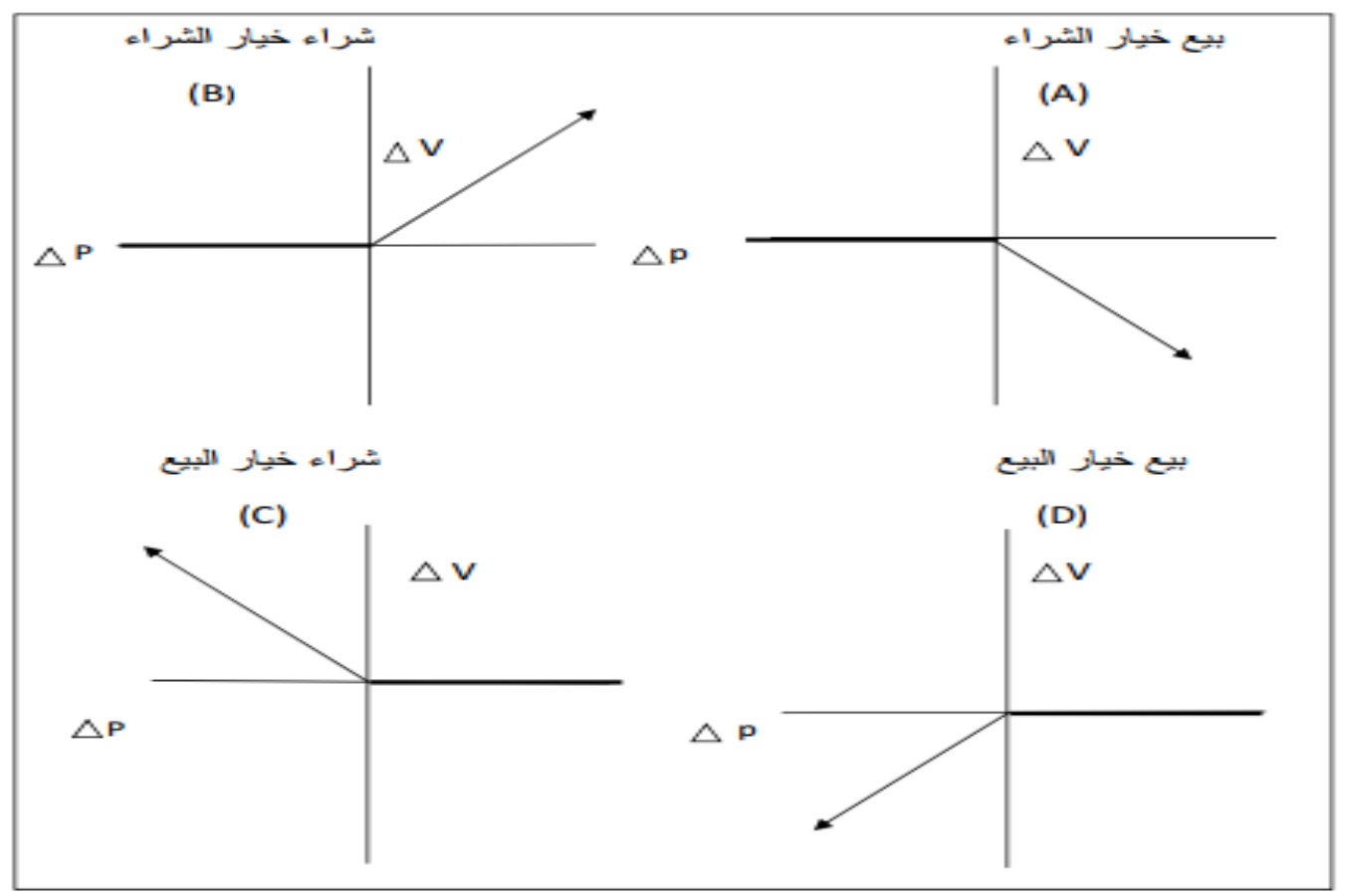

شكل (1): استراتيجيات الخيارات المتبعة في إدارة الدخاطر

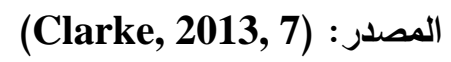

$$
\text { • كما يرى (Revsine) أن استخدامات التحوط في ثلاث حالات هي :- }
$$

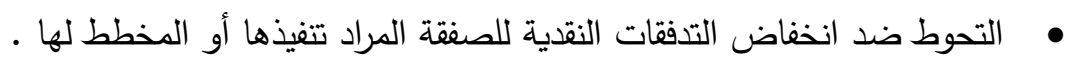

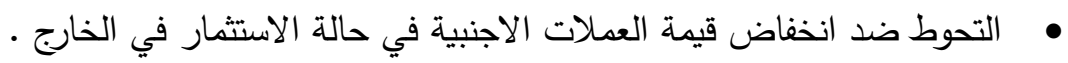

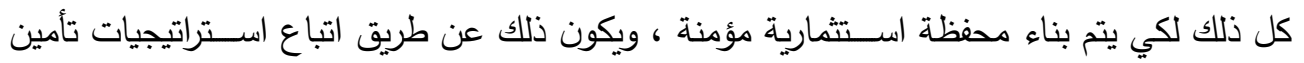

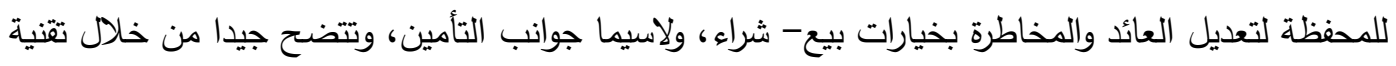

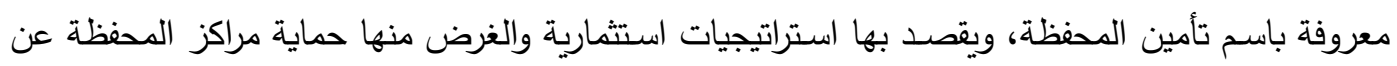
طريق توفير عائدا أدنى على المحفظة مع توفير فرصة للمحفظة في الوقت نفسه للاشتراك في جني الأرباح

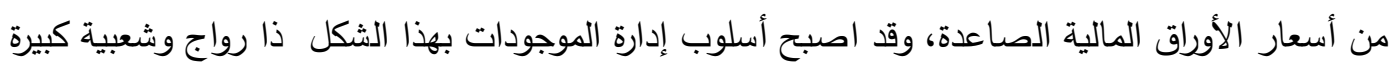

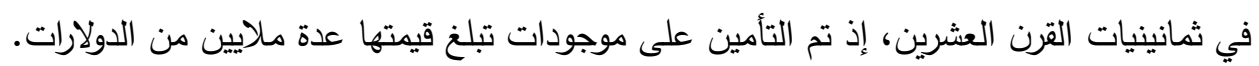

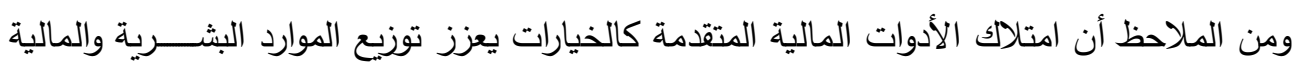

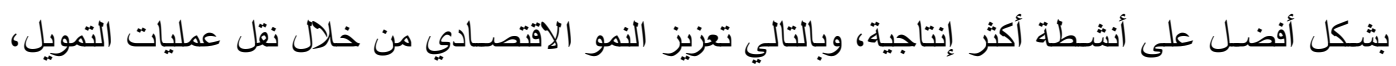


ولهذا يميل المستثمرون إلى الاستثمار في المشاريع ذات العوائد المرتفعة التي يظهر أنها تتمتع بفرص توزيع أفضل لرأس مال شركة معينة وزيادة درجة رفاهية الاستثمار .

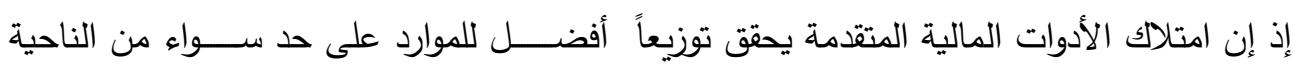

إن الأسـواق المالية المعاصــرة تعمل في ظل بيئة عدم اليقين أي المخاطرة والتقلب المسـتمر وعدم

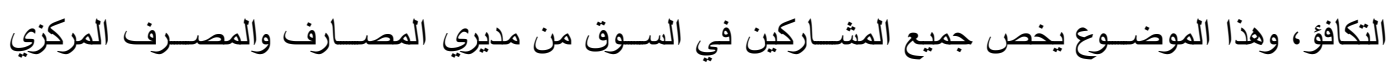

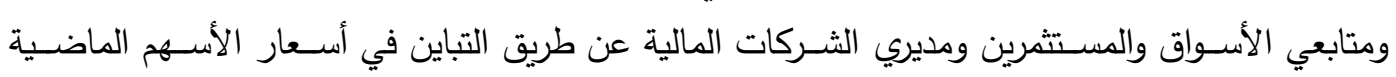

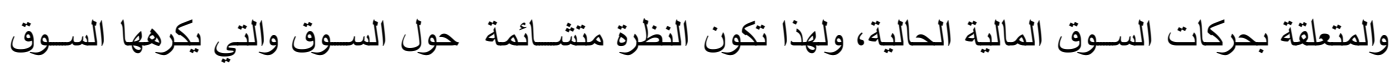

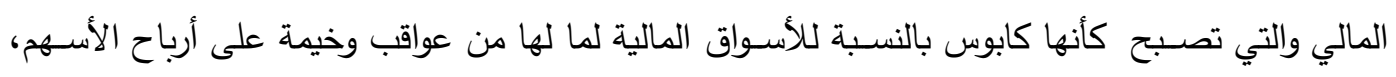

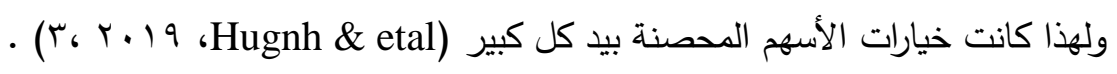

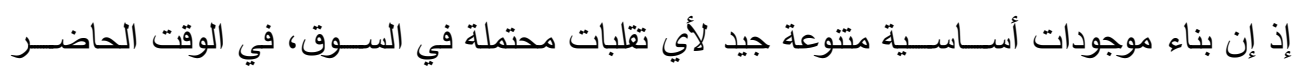

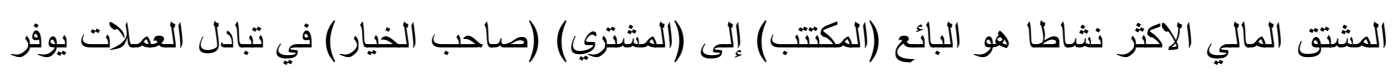

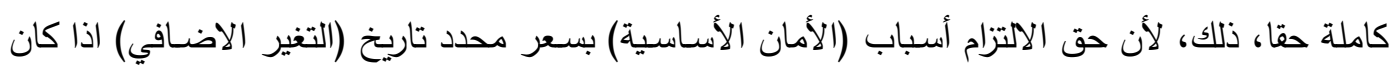

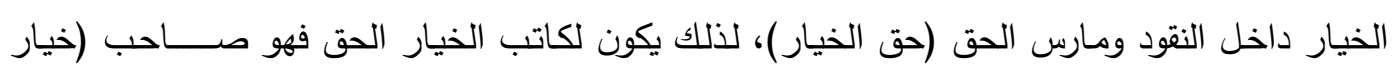
الاسـتدعاء) أو يقبل تسـليم العنصـر الاسـاسـي، ولهذا يقومون بيناء محفظة مناسـبة من خلال اسـتخدام

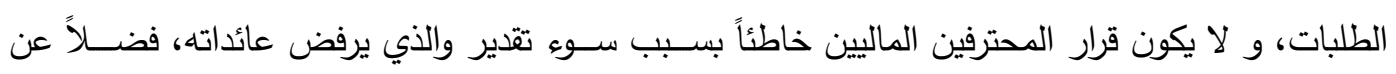
الدوافع لاستخدام الخيار في تحركات السوق السلبية المعاكسة.

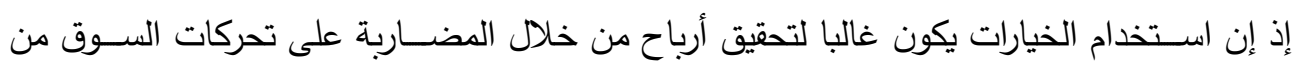

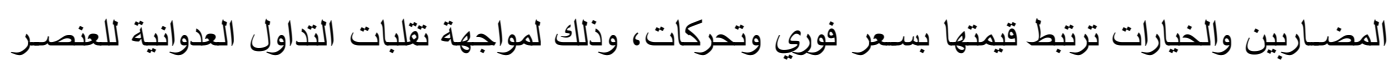

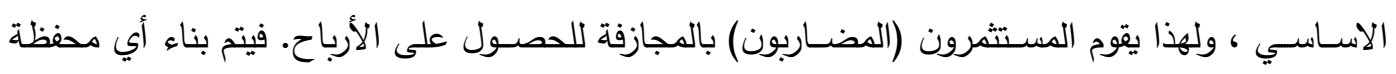

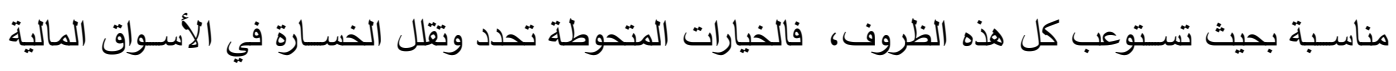

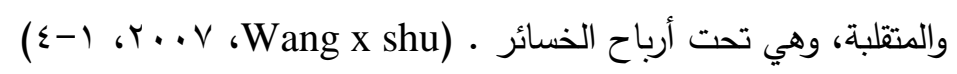

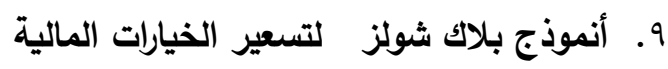

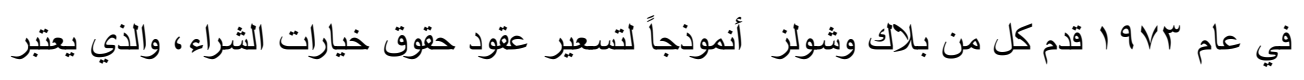

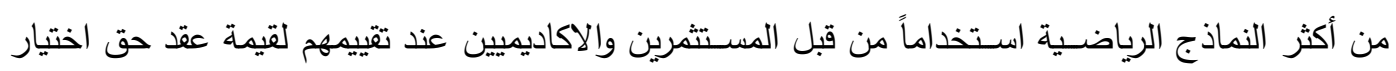

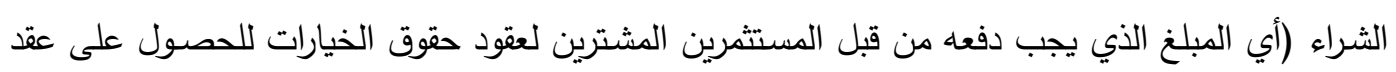

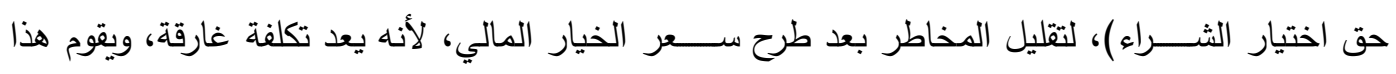

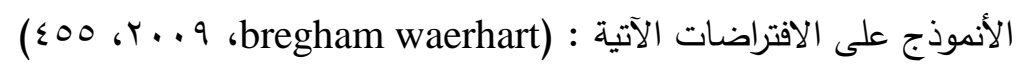
أ. الاتوجد تكلفة معاملات.

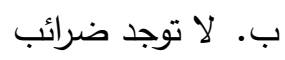


ج. معدل الفائدة الخالي من خطر المخاطرة ثابت لايتغير • دعل د. تعمل السوق المالية بشكل مستمر. هـ تتميز أسعار الأسهم بحركة ذات استقرار نسبي (لايوجد ارتفاع او انخفاض مفاجئ).

$$
\text { و. لاتوجد توزيعات أرباح. }
$$

ز · أن يكون حق الاختيار من النوع الاوربي وليس الامريكي.

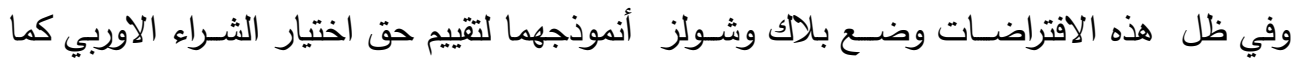

موضح في المعادلة الآتية : (Hull,2008,246)

$\mathrm{V}=\mathrm{P}[\mathrm{N}(\mathrm{d} 1)]-[\mathrm{N}(\mathrm{d} 2)] \mathrm{Xe}-r^{R F t}$

$\mathrm{d} 1 \frac{\operatorname{Ln}\left(\frac{\mathrm{P}}{\mathrm{X}}\right)+\left[\boldsymbol{r}_{\boldsymbol{R}}+\left(\frac{\mathrm{o}^{2}}{2}\right)\right] \mathrm{T}}{\sigma \sqrt{\boldsymbol{t}}}$

$\mathrm{d} 2=\mathrm{d} 1-\quad-o r \sqrt{t}$

إذ إن : - n

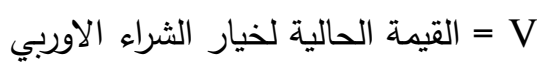

P السعر الحالي للسهر (سعر التنفيذ) P(1) P

d1 القيمة التراكمية للتوزيع الطبيعي عند النقطة N(d1)

d2 القيمة التراكمية للتوزيع الطبيعي عند النقطة N(d2)

$$
\text { سعر السهم في تاريخ الانتهاء }
$$

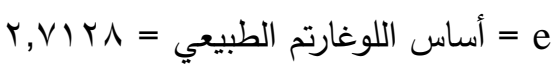

= معدل الفائدة الخالي من الخطر $=r_{F R}$

الفترة المنقضية بين تاريخ التعاقد وتاريخ الانتهاء في صورة نسبة مؤية من السنة

P/X اللوغارتم الطبيعي لـ Ln(P/X)

$$
\text { = } \text { o }^{2}
$$

• ا.توقع اتجاه السوق باستخدام مؤشر الستوكاستك

يستخدم مؤشر الستوكاستك للتعرف على اتجاه سوق الأوراق المالية وكذلك فيما إذا كان السوق يمر

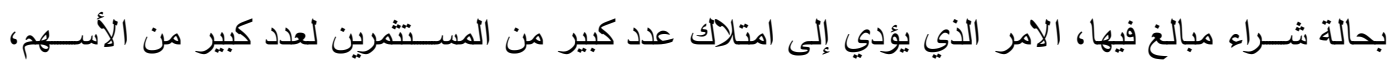

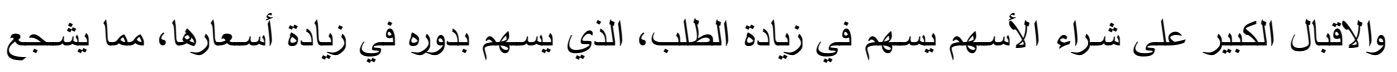

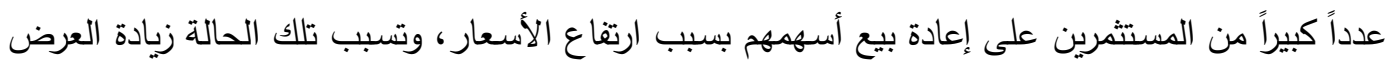

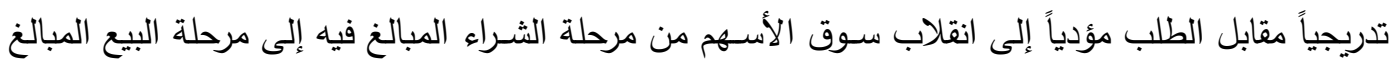




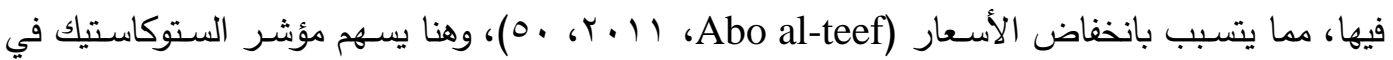

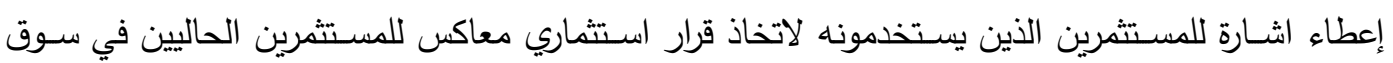

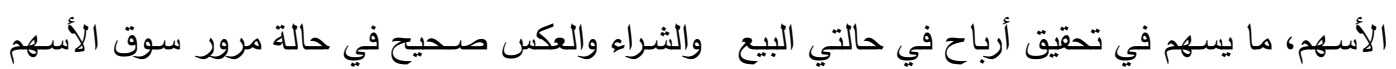

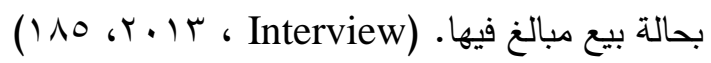

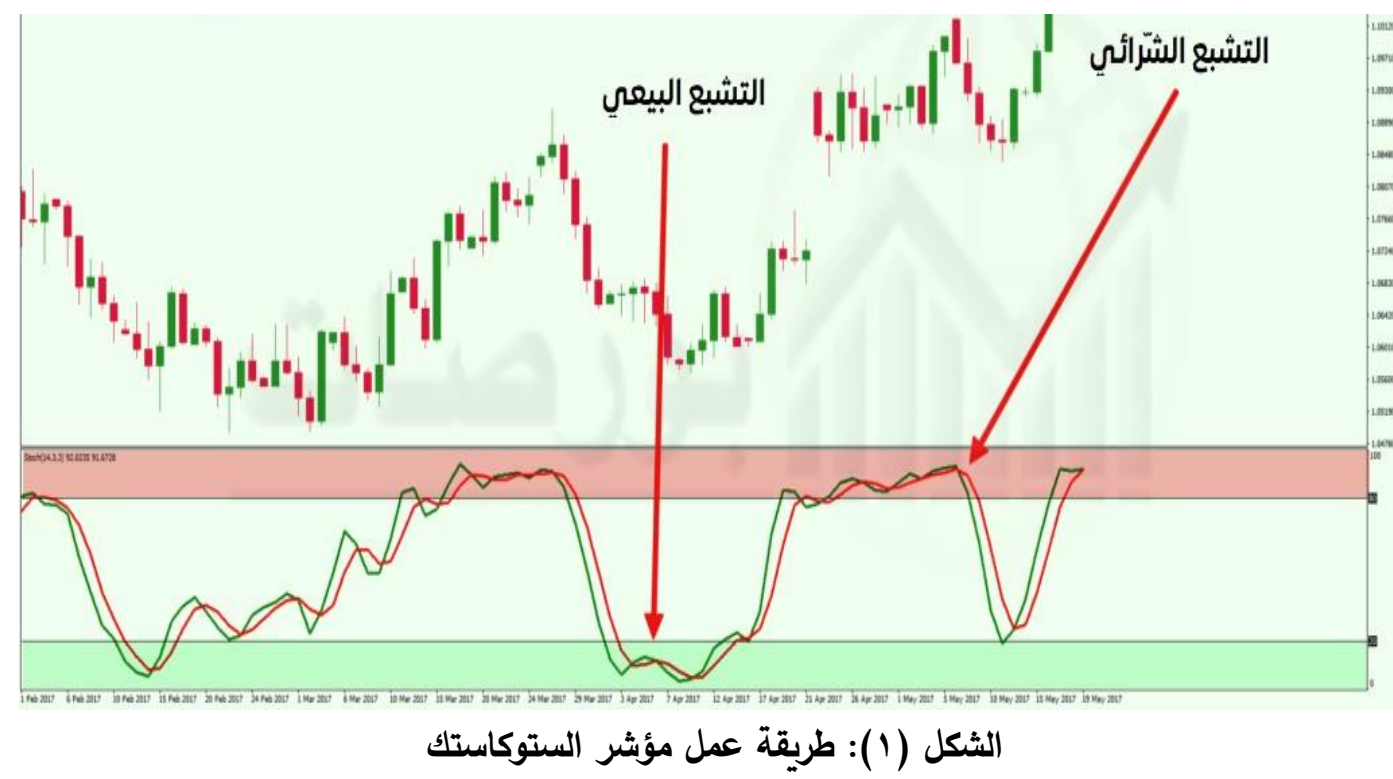

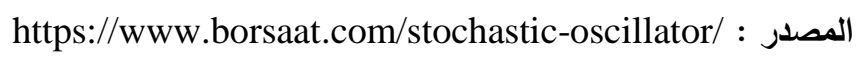

ثانياً : تسعير الخيارات المالية لتحديد حجم الأرباح والخسائر (المخاطر) للمستثرين في سوق دبي للأورلق

\section{المالية}

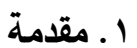

يركز الجانب العملي على بيان الطريقة التي يستخدها المستثمرين لتسعير الخيارات المالية لعينة البحث الامر الذي يساعدهم في تحديد حجم الخسائر التي سوف يتكبدونها بشكل دقيق في حال كانت توقعاتهم لئن

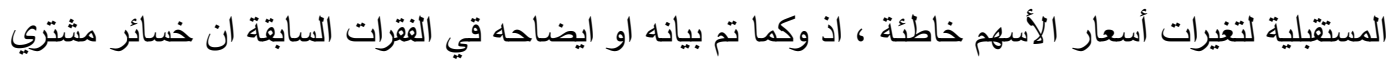
حقوق الاختيار محدودة بمقدار العلاوة التي يدفعونها إلى محرري الخيارات المالية، اما بالنسبة للأرباح

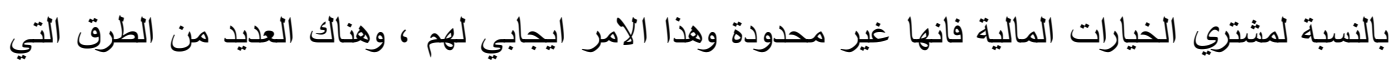

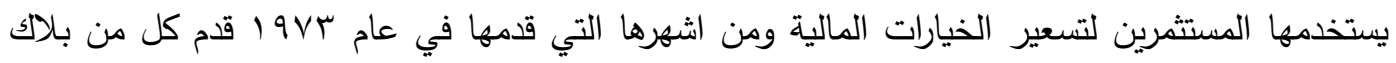
وشولز أنموذجاً لتسعير عقود حقوق اختيارات الثراء والبيع، والذي يعتبر من اكثر النماذج الرياضية استخداماً من قبل المستثرين والاكاديميين عند تقييمهم لخيارات (اي المبلغ الذي يجب دفعها المستثمرين المشترين لعقود

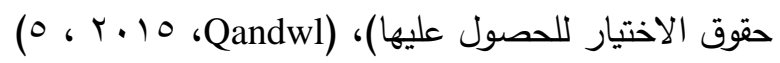




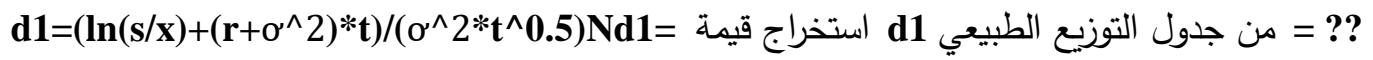

$\mathrm{d} 2=\mathrm{d} 1-\sigma^{*} \mathrm{t}^{\wedge} \mathrm{0.5}$

Nd2= من جدول التوزيع الطبيعي d2 = استخراج قيمة = ?

$\mathrm{V}=\mathrm{s} * \mathrm{nd1}-\mathrm{x} * \exp (-\mathrm{t} * \mathbf{r}) * \mathrm{nd} 2$

P

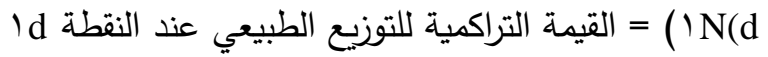

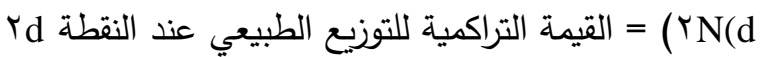

$$
\begin{aligned}
& \text { سعر السهم في تاريخ الانتهاء }=\text { X } \\
& \text { Y,V) Y = أساس اللوغارتم الطبيعي لe =e } \\
& \text { = معدل الفائدة الخالي من الخطر }=r_{F R}
\end{aligned}
$$

t الفترة المنقضية بين تاريخ التعاقد وتاريخ الانتهاء في صورة نسبة مؤية من السنة

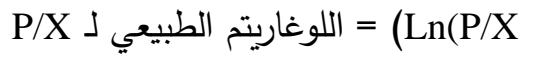$$
\text { = }{ }^{2}
$$

ومن أجل تسعير الخيارات المالية لابد من توافر الشروط المذكورة آنفاً التي قسم منها متوفر مباشرة

(السعر الحالي للسهم و سعر السهم المتوقع في تاريخ الانتهاء و أساس اللوغارتم الطبيعي و معدل الفائدة الخالي من الخطر و الفترة المنقضية بين تاريخ التعاقد وتاريخ الانتهاء في صورة نسبة مئوية من السنة)

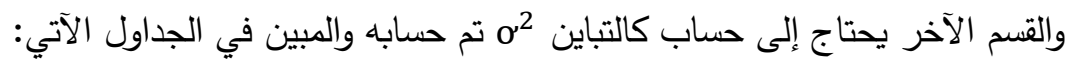

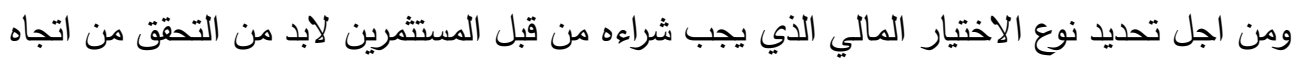

سوق السهر من خلال العديد من الطرائق، ومنها مؤشر ستوكاستيك المستخدم في البحث.

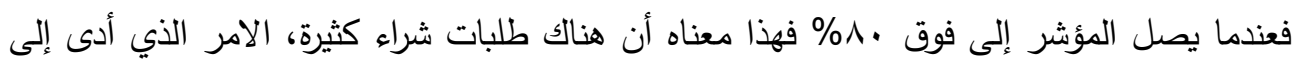

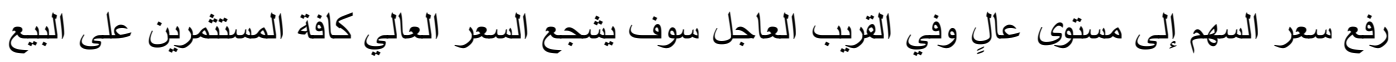
في المستقبل القربب، الامر الذي يعطي إثارة إلى أن الأسعار في المستقبل سوف تتخفض مدا يساعد

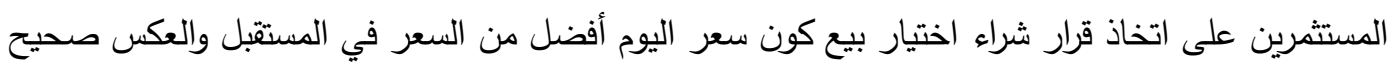

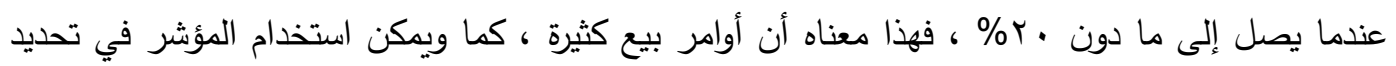

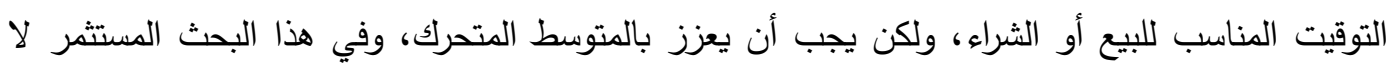

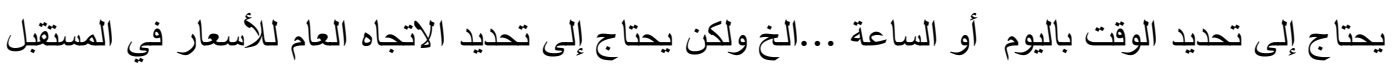
القريب، ويحسب مؤشر الستوكاستيك من خلال المعادلة الاتية ادناه: 


\begin{tabular}{|c|c|c|c|c|}
\hline اقل سعر للسهح خلال & - & اخر سعر للسهة خلال & 100 & مؤشر ستو كاستيك لس \\
\hline اقل سعر للسهر خلال & - & اعلى ستر للسهم خلال & $x$ & \\
\hline
\end{tabular}

إذ إن :

• آخر سعر للسهم خلال الفترة n : وهي الفترة التي عادة ما تكون ع ا يوم تداول.

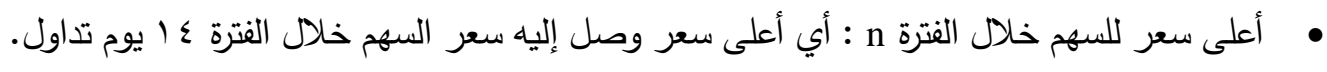
• أقل سعر لسهم خلال الفترة n : اي اقل سعر وصل إليه السهم خلال الفترة عـ إيوم تداول.

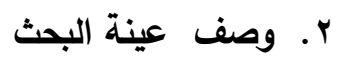

تبين الجداول أدناه كيفية احتساب مؤشر الستوكاستيك والتباين للمصارف عينة البحث المبينة في

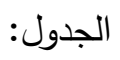

جدول (1): الثركات والمصارف عينة البحث

\begin{tabular}{|c|c|c|}
\hline الملاحظات & اسم المصرف & $ت$ \\
\hline تم استخدامه في البحث & مصرف عجمان ش.م·ع & 1 \\
\hline تم استخدامه في البحث & مصرف السلام السودان & 2 \\
\hline تم استخدامه في البحث & أملاك للتمويل ش•م•ع & 3 \\
\hline تم استخدامه في البحث & مجموعة جي اف اتش المالية ش.م.ب & 4 \\
\hline تم استخدامه في البحث & شركة الإثمار القابضة ش.م.ب & 5 \\
\hline تم استخدامه في البحث & الخليجي التجاري ش.م.ب & 6 \\
\hline
\end{tabular}

https://marketwatch.dfm.ae المصدر : من إعداد الباحثة بالاعتماد على البيانات المنشورة في سوق دبي للأوراق المالية في في في

يبين الجدول (1) الثركات المالية (المصارف) التي تمثل القطاع المالي في سوق دبي للأوراق المالية، إذ

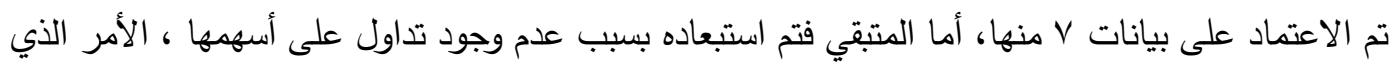
لايساعد في التنبؤ بأسعارها في المستقبل، مما يضع المستثمرين في حيرة من أمرهم هل يشترون اختيار بيع أم شراء. 
1. التعير الخيارات المالية لعينة البحث

بعد وصف عينة البحث نقوم بإجراء التحليل على البيانات الخاصة بها وكما يأتي :

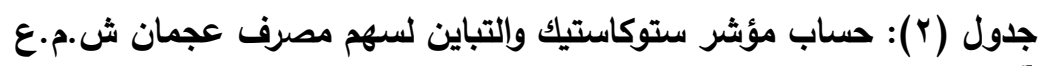

\begin{tabular}{|c|c|c|c|c|c|c|c|c|c|c|}
\hline \multicolumn{5}{|c|}{ حصاب الثباين لعائد سهم مصرئ عجمان ش.م.ع } & \multicolumn{6}{|c|}{ 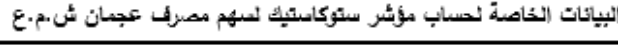 } \\
\hline 10 & 9 & 8 & 7 & 6 & 5 & 4 & 3 & 2 & 1 & ألعمود \\
\hline 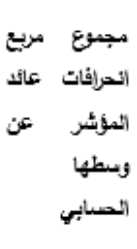 & 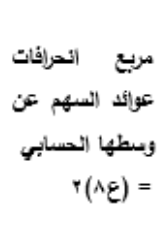 & 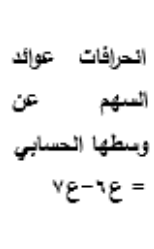 & "الوصابي & 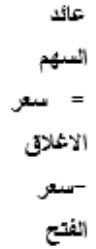 & الإثلالى & سعر & سعر & سنقع & انثاريغ & $ت$ \\
\hline 0.014434 & 0.120142 & -0.048571 & 0.071571 & 0.023 & 0.965 & 0.932 & 0.965 & 0.942 & $8 / 8 / 2019$ & 1 \\
\hline 0.032451 & 0.180142 & -0.108571 & 0.071571 & -0.037 & 0.94 & 0.94 & 0.98 & 0.977 & $7 / 8 / 22019$ & 2 \\
\hline 0.015164 & 0.123142 & -0.051571 & 0.071571 & 0.02 & 0.95 & 0.922 & 0.95 & 0.93 & $6 / 8 / 2019$ & 3 \\
\hline 0.620720 & -0.787858 & 0.859429 & 0.071571 & 0.931 & 0.931 & 0 & 0 & 0 & 5/8/2019 & 4 \\
\hline 0.025009 & 0.158142 & -0.086571 & 0.071571 & -0.015 & 0.931 & 0.931 & 0.946 & 0.946 & 4/8/2019 & 5 \\
\hline 0.018535 & 0.136142 & -0.064571 & 0.071571 & 0.007 & 0.959 & 0.946 & 0.959 & 0.952 & $1 / 8 / 2019$ & 6 \\
\hline 0.020490 & 0.143142 & -0.071571 & 0.071571 & 0 & 0.952 & 0.952 & 0.953 & 0.952 & $31 / 7 / 2019$ & 7 \\
\hline 0.018535 & 0.136142 & -0.064571 & 0.071571 & 0.007 & 0.952 & 0.945 & 0.965 & 0.945 & $30 / 7 / 2019$ & 8 \\
\hline 0.017994 & 0.134142 & -0.062571 & 0.071571 & 0.009 & 0.96 & 0.951 & 0.96 & 0.951 & 29/7/2019 & 9 \\
\hline 0.020204 & 0.142142 & -0.070571 & 0.071571 & 0.001 & 0.95 & 0.935 & 0.95 & 0.949 & 28/7/2019 & 10 \\
\hline 0.020204 & 0.142142 & -0.070571 & 0.071571 & 0.001 & 0.941 & 0.935 & 0.95 & 0.94 & $25 / 7 / 2019$ & 11 \\
\hline 0.015411 & 0.124142 & -0.052571 & 0.071571 & 0.019 & 0.94 & 0.921 & 0.945 & 0.921 & $24 / 7 / 2019$ & 12 \\
\hline 0.015411 & 0.124142 & -0.052571 & 0.071571 & 0.019 & 0.94 & 0.921 & 0.945 & 0.921 & 23/72019 & 13 \\
\hline 0.015912 & 0.126142 & -0.054571 & 0.071571 & 0.017 & 0.935 & 0.918 & 0.935 & 0.918 & $22 / 7 / 2019$ & 14 \\
\hline 0.870474 & & & ألمجموع & 1.0020 & & & & & & المجموع \\
\hline 0.062177 & & & ألثباين & 0.0716 & & & & Los & $=$ & 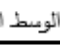 \\
\hline
\end{tabular}

المصدر: من اعداد الباحثة بالاعتماد على بيانات المصرف المنشورة في سوق دبي للأوراق المالية https://marketwatch.dfm.ae

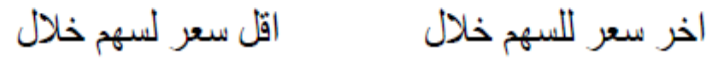

$$
\begin{aligned}
& \text { مؤشر ستوكاستيك لسهم مصرف } \\
& \text { الفترة } \\
& 27.4=\begin{array}{cccccc}
0.918 & - & 0.935 & 100 & \times & 0.98 \\
0.918 & - & 0.98 &
\end{array} \\
& \text { يبين الجدول (r) عملية حساب مؤشر ستوكاستيك والتباين لمصرف عجمان ش.م.ع التي يحتاج إليها } \\
& \text { المستثرون في اتخاذ قراراتهم الاستثمارية شراء خيار شراء أو بيع خيار شراء ، إإذ يبين مؤشر ستوكاستيك }
\end{aligned}
$$

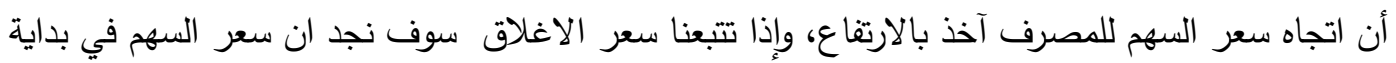

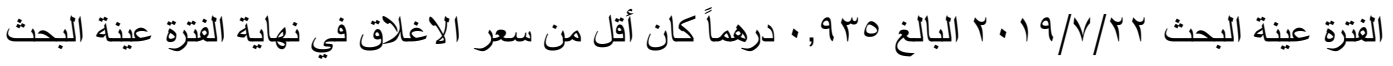

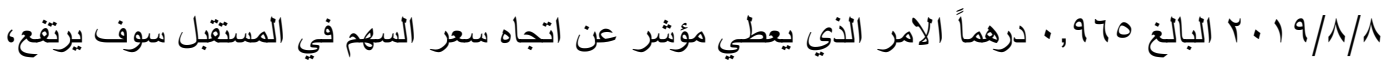

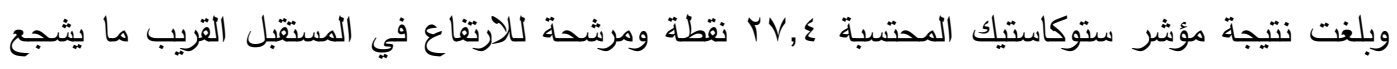


المستثرين على الاقبال على شرائه ، وهنا يستطيع المستثرون الاستفادة من ذلك وتسخيره لمصلحتهم في اختيار الخيارات المالية المناسبة لهح ، وبما أن سعر السهم سوف يرتئ ئفع في المستقبل فمن مصلحة المستثر أن يثتري خيار شراء للسهم بسعر اليوم كونه يعد اقل من المستقبل (سوف يرتفع) وبالتالي إذا صحت توقعات المستثرين فإنهم سوف يحققون أرباحاً مجزية، وإن كانت توقعاتهم غير صحيحة سوف لتهرئ تكون خسائرهم محدودة بقيمة العلاوة الني دفعوها لمحرر خيار الثراء (أي إن المستثمر يعرف مقدماً كم سوف يخسر ، وهذا شيء

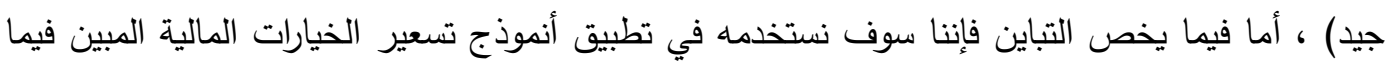
: يأتي

$\mathrm{d} 1=\left(\ln (\mathbf{0 . 9 6 5 / 0 . 9 3 5})+\left(\mathbf{0 . 0 3}+0.0622^{\wedge} 2 / 2\right) * \mathbf{0 . 5} / 0.0622^{*} \mathbf{0 . 5} \mathbf{5}^{\wedge} \mathbf{0 . 5}=1.08\right.$

Nd1= 0.86

d2=1.08- $0.0622 * 0.5^{\wedge} 0.5=1.08-0.0439820=1.04$

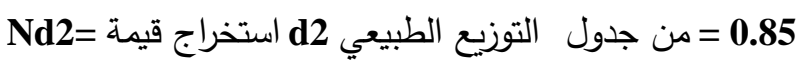

$\mathrm{V}=\mathrm{s} * \mathrm{nd1}-\mathrm{x} * \exp (-\mathrm{t} * \mathbf{r}) * \mathrm{nd} 2$

$\mathbf{V}=\mathbf{0 . 9 6 5} * \mathbf{1 . 0 8 - 0 . 9 3 5} * 2.7183^{-0.03 * 0.5 * 0.85}$

V=0.05 درهم سعر أو مبلغ العلاوه لخيار الشراء الواحد

وبما أن المستثمر أصبح باستطاعته تحديد قيمة الخيار المالي البالغة ه.., • درهم فإنه بذلك قام بتحديد مبلغ العلاوة التي سوف يدفعها مقابل الحصول على خيار مالي واحد والتي تعتبر أيضاً أعلى خسارة

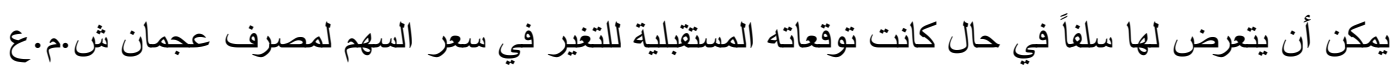
خاطئة ، أما إذا صحت توقعات المستثمر فإنه سوف يحقق أرباحاً ، وبما أننا نتعامل مع المستثبل، فيمكن

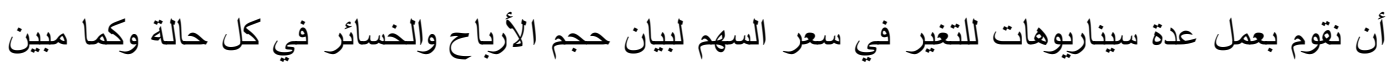

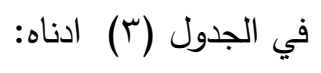

جدول (r): سيناريوهات تغير سعر سهم مصرف عجمان ش.م.ع

\begin{tabular}{|c|c|c|c|c|c|c|c|c|c|c|c|c|}
\hline إنم المبلغ المستئمر & المستئر & الخسارة للمحرد الزبع او & صافي الزيخ او & & العلاوة & & الخيار حثى & & التحفيذ & & المثوقع & ت \\
\hline $100 \%$ & لاينظة & 0.05 & 0.05 & $=$ & 0.05 & 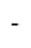 & 0 & $=$ & 0.935 & - & 0.1 & 1 \\
\hline $0 \%$ & نقطة الثعادل & 0 & 0 & $=$ & 0.05 & - & 0.05 & $=$ & 0.935 & - & 0.985 & 2 \\
\hline $530 \%$ & ئفذ & $0.265-$ & 0.265 & $=$ & 0.05 & - & 0.315 & $=$ & 0.935 & - & 1.25 & 3 \\
\hline
\end{tabular}

المصدر : من إعداد الباحثة بالاعتماد على جدول (r).

تبين من خلال تحليل مؤشر ستووكاستيك أن سعر السهم لمصرف عجمان سوف يرتفع في المستقبل لذلك بمقدور المستثمر شراء خيار شراء ، ويبين الجدول (r) ثلاثة سيناريوهات للتغير في سعر السهم لبيان حجم الأرباح والخسائر للمستثمرين مشتري خيار الشراء ومحرري خيار الشراء (البائعين للخيارات المالية) وكما مبين في الفقرات ا-ب في الجدول وفيما يأتي توضح لكل منها: 
أ. تبين الفقرة ا من الجدول (r) ان سعر السهم مهما انخفض فان المستثر من حقه تتفيذ أو عدم

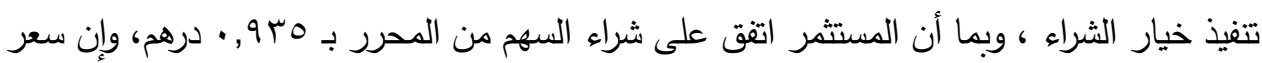

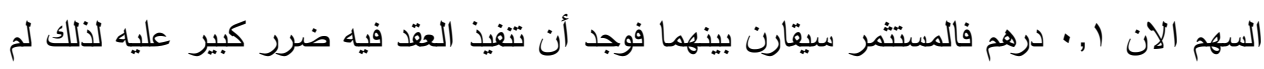

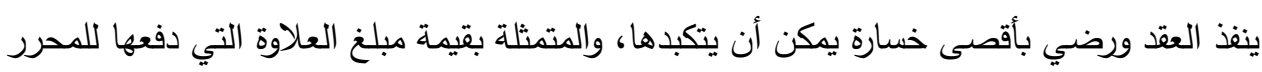

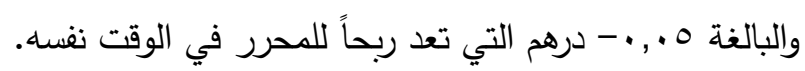

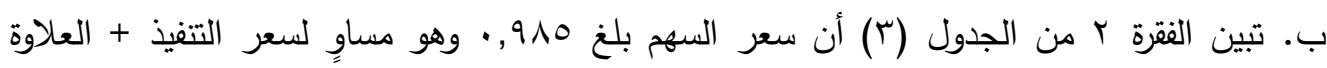

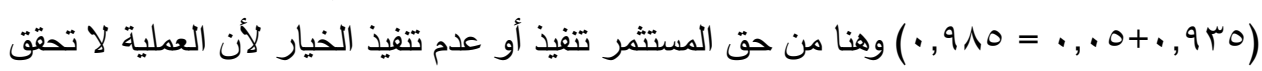
له لا ربحاً والخسارة (نقطة التعادل).

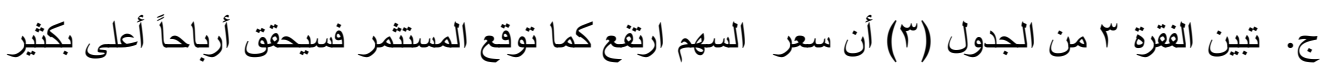

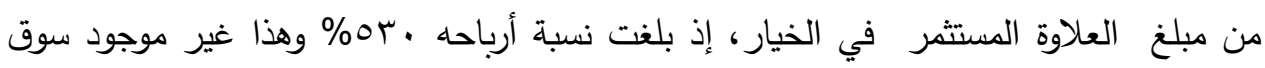

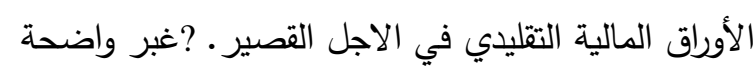
د. إذا كان المستثمر يستثمر في السوق التقليدي فإنه يستطيع تسخير الخيارات المالية لتقليل الخسائر فيه من خلال اتخاذ مركز استثماري معاكس في سوق الخيارات المالية، وبالتالي فإن ما يخسره في لئي السوق التقليدي يكسبه في سوق الخيارات مقلاً بذلك الخطر الذي يتعرض لـه في المستقبل. جدول ( ) ): حساب مؤشر ستوكاستيك والتباين لسهم مصرف السلام السودان

\begin{tabular}{|c|c|c|c|c|c|c|c|c|c|c|}
\hline \multicolumn{5}{|c|}{ حساب انثباين لعائد سهم مصريل عجمان ش.م.ع } & \multicolumn{6}{|c|}{ الثيائات الخاصة نحساب مزئر ستوكاستيك لهنه مصرب عجمان } \\
\hline 10 & 9 & 8 & 7 & 6 & 5 & 4 & 3 & 2 & 1 & ألعثود \\
\hline 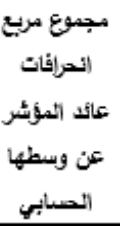 & 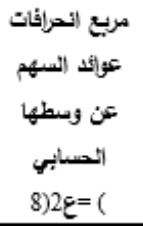 & 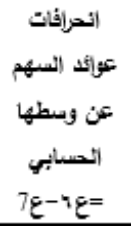 & 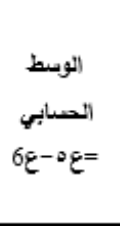 & الائل السلاف - سعر & الإثلادق سعر & سنم & 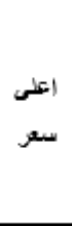 & |الفقبح & التدابيخ & $\Xi$ \\
\hline $\begin{array}{l}0.107022 \\
0.581952 \\
0.727367 \\
0.581952 \\
0.581952 \\
0.088293 \\
0.088293 \\
0.581952 \\
0.107022 \\
0.677095 \\
0.727367 \\
0.351481 \\
0.088293 \\
0.508167 \\
\end{array}$ & $\begin{array}{c}-0.327142 \\
0.762858 \\
0.852858 \\
0.762858 \\
0.762858 \\
-0.297142 \\
-0.297142 \\
0.762858 \\
-0.327142 \\
0.822858 \\
0.852858 \\
0.592858 \\
-0.297142 \\
0.712858 \\
\end{array}$ & $\begin{array}{c}0.708571 \\
-0.381429 \\
-0.471429 \\
-0.381429 \\
-0.381429 \\
0.678571 \\
0.678571 \\
-0.381429 \\
0.708571 \\
-0.441429 \\
-0.471429 \\
-0.211429 \\
0.678571 \\
-0.331429 \\
\end{array}$ & $\begin{array}{l}0.381429 \\
0.381429 \\
0.381429 \\
0.381429 \\
0.381429 \\
0.381429 \\
0.381429 \\
0.381429 \\
0.381429 \\
0.381429 \\
0.381429 \\
0.381429 \\
0.381429 \\
0.381429 \\
\end{array}$ & $\begin{array}{c}1.0900 \\
0.0000 \\
-0.0900 \\
0.0000 \\
0.0000 \\
1.0600 \\
1.0600 \\
0.0000 \\
1.0900 \\
-0.0600 \\
-0.0900 \\
0.1700 \\
1.0600 \\
0.0500 \\
\end{array}$ & $\begin{array}{c}1.09 \\
1.09 \\
1.01 \\
1.1 \\
1.04 \\
1.06 \\
1.06 \\
1.06 \\
1.09 \\
1.09 \\
1.08 \\
1.17 \\
1.06 \\
1.06\end{array}$ & $\begin{array}{c}0 \\
1.09 \\
1.01 \\
1.10 \\
1.04 \\
0 \\
0 \\
1.06 \\
0 \\
1.09 \\
1.08 \\
0.985 \\
0 \\
1.01\end{array}$ & $\begin{array}{c}0 \\
1.09 \\
1.12 \\
1.10 \\
1.04 \\
0 \\
0 \\
1.06 \\
0 \\
1.15 \\
1.19 \\
1.17 \\
0 \\
1.06\end{array}$ & $\begin{array}{c}0 \\
1.09 \\
1.1 \\
1.1 \\
1.04 \\
0 \\
0 \\
1.06 \\
0 \\
1.15 \\
1.17 \\
1 \\
0 \\
1.01\end{array}$ & $\begin{array}{c}8 / 8 / 2019 \\
7 / 8 / 22019 \\
6 / 8 / 2019 \\
5 / 8 / 2019 \\
4 / 8 / 2019 \\
1 / 8 / 2019 \\
31 / 7 / 2019 \\
30 / 7 / 2019 \\
29 / 7 / 2019 \\
28 / 7 / 2019 \\
25 / 7 / 2019 \\
24 / 7 / 2019 \\
23 / 72019 \\
22 / 7 / 2019 \\
\end{array}$ & $\begin{array}{l}1 \\
2 \\
3 \\
4 \\
5 \\
6 \\
7 \\
8 \\
9 \\
10 \\
11 \\
12 \\
13 \\
14\end{array}$ \\
\hline $\begin{array}{l}5.798209 \\
0.414158\end{array}$ & & & المجبوع & $\begin{array}{l}5.3400 \\
0.3814\end{array}$ & & & & & تحسابِي & |المجسوع \\
\hline
\end{tabular}

المصدر: من إعداد الباحثة بالاعتماد على بيانات المصرف المنشورة في سوق دبي للأوراق المالية https://marketwatch.dfm.ae 


$$
\begin{aligned}
& \text { اخر سعر للسهم خلال اقل سعر لسهم خلال } \\
& \text { مؤشر ستوكاستيك لسهم مصرف السلام }
\end{aligned}
$$

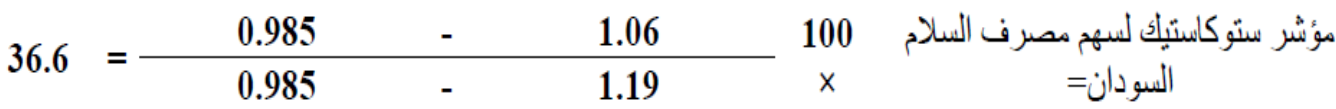

يبين الجدول (ع) عملية احتساب مؤشر ستوكاستيك والتباين لمصرف السلام السودان التي يحتاج إليها

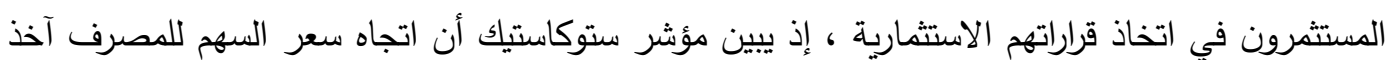

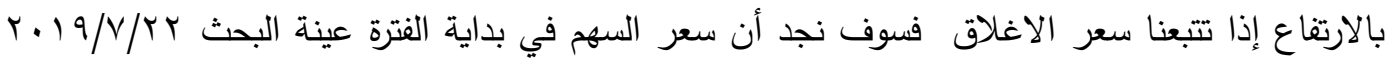

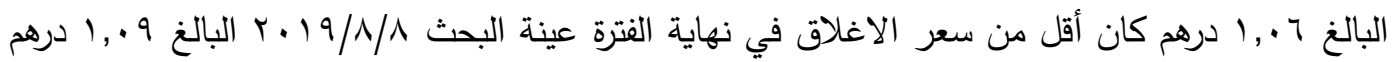
الامر الذي يعطي مؤشر عن اتجاه سعر السهم في المستقبل سوف يرتقع ، وبلغت نتيجة مؤشر ستوكاستيك المحتسبة 7, ؟r نقطة ومرشحة للارتفاع في المستقبل القريب ما يشجع المستثرين على الاقبال على شرائه،

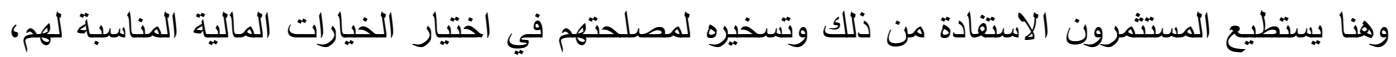
وبما أن سعر السهم سوف يرتفع في المستقبل فمن مصلحة المستثمر أن يشتري خيار شراء للسهم بسعر اليوم كونه يعد أقل من المستقبل (سوف يرتفع) وبالتالي إذا صحت توقعات المستثمرين فإنهم سوف يحققون أرباحاً مجزية، وإن كانت توقعاتهم غير صحيحة فسوف تكون خسائرهم محدودة بقيمة العلاوة التي دفعوها للمحرر خيار الثراء (أي إن المستثر يعرف مقدماً كم سوف يخسر وهذا شيء جيد) ، أما فيما يخص التباين فسوف يتم اعتماده في تطبيق أنموذج تسعير الخيارات المالية المبين فيما يأتي :

d1 $=(\ln (1.09 / 1.06)+(0.03+0.414158 \wedge 2 / 2) * 0.5 / 0.414158 * 0.5 \wedge 0.5=0.29 N d 1=0$

d1 0.62

d2=0.29- $0.414158 * 0.5^{\wedge} 0.5=0.29-0.29=0.00$

Nd2=0.50 $=0$

$\mathrm{V}=\mathrm{s} * \mathrm{nd1-x}$ *exp(-t*r)*nd2

$\mathbf{V}=\mathbf{1 . 0 9} * \mathbf{0 . 6 2 - 1 . 0 6} * 2.7183^{-0.03 * 0.5 * 0.50}$

درهم سعر خيار الثراء الواحد V=0.15

وبما أن المستثر اصبح باستطاعته حساب قيمة الخيار المالي البالغة ه.., • درهم فإنه بذلك قام بتحديد مبلغ العلاوة التي سوف يدفعها مقابل الحصول على خيار مالي واحد والتي تعتبر أيضاً أعلى خسارة

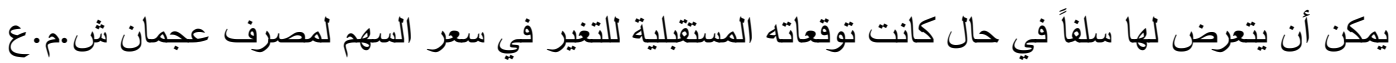

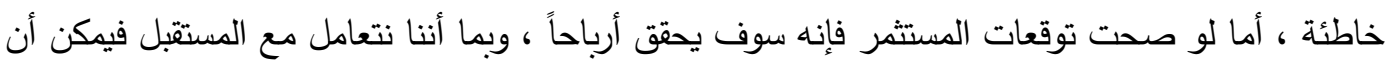
نقوم بعمل عدة سيناريوهات للتغير في سعر السهم لبيان حجم الأرباح في كل حالة وكما مبين ادناه : 
جدول (0): سيناريوهات تغير سعر مصرف السلام السودان

\begin{tabular}{|c|c|c|c|c|c|c|c|c|c|c|c|c|}
\hline والتربح إلى المبلغ الكمارة & المستثمر & صافي الربت & صافي الربع & & العلاوة & & هيمة حق الكيار & & التئفيذ & & المتوقع & $ت$ \\
\hline $100 \%$ & 0.05 & 0.05 & 0 & $=$ & 0.15 & - & $0.21-$ & $=$ & 1.06 & - & 0.1 & 1 \\
\hline $0 \%$ & نقطة تعادل & 0 & 0 & $=$ & 0.15 & - & 0.15 & $=$ & 1.06 & - & 1.21 & 2 \\
\hline $193 \%$ & 0.29 & 0.29 & 0.29 & $=$ & 0.15 & - & 0.44 & $=$ & 1.06 & - & 1.5 & 3 \\
\hline
\end{tabular}

المصدر : من إعداد بالاعتماد على جدول (ع)

تبين من خلال تحليل مؤشر ستوكاستيك أن سعر السهم لمصرف عجمان سوف يرتفع في المستقبل لذلك بمقدور المستثمر شراء خيار شراء ، ويبين الجدول (0) ثلاثة سيناريوهات للتغير في سعر السهم لبيان حجم الأرباح والخسائر للمستثمرين مشتري خيار الثراء ومحرري خيار الشراء (البائعين للخيارات المالية)

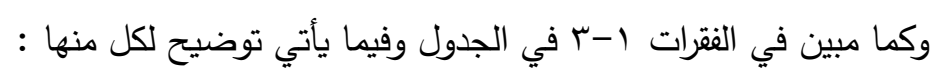

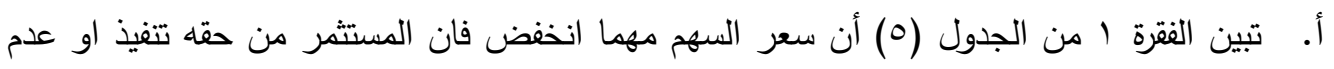

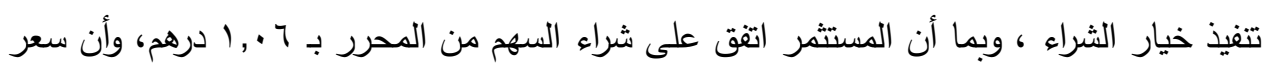

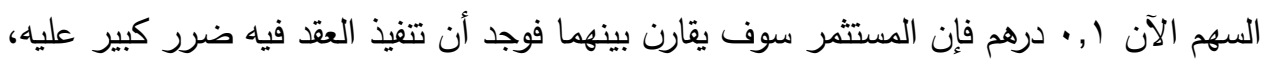

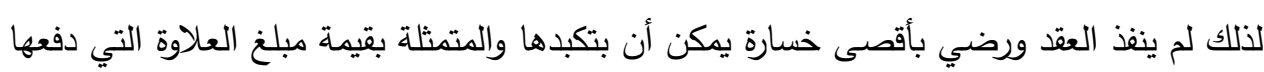

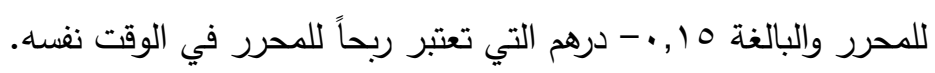

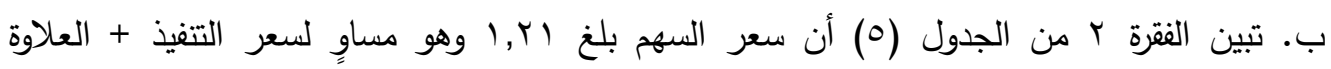

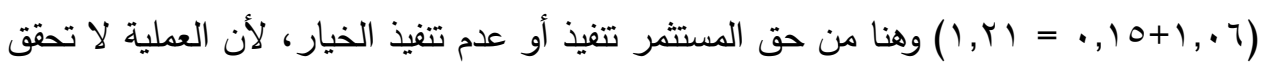

$$
\text { له لا ربحاً ولإخسارة (نقطة التعادل). }
$$

ج. تبين الفقرة r من الجدول (0) أن سعر السهم ارتقع كما توقع المستثر فإنه سوف يحقق أرباحاً

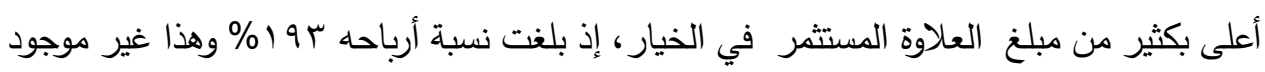

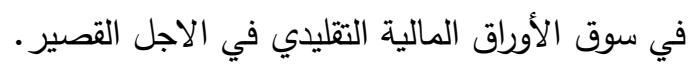
د. إذا كان المستثمر يستثمر في السوق التقليدي فإنه يستطيع تسخير الخيارات المالية لتقليل الخسائر

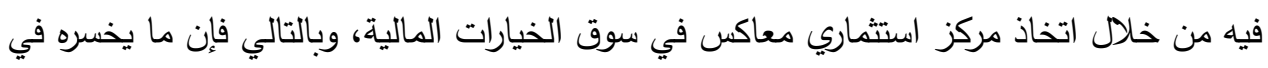
السوق التقليدي يكسبه في سوق الخيارات ما يقلل الخطر الذي يتعرض له في المستقبل. 
جدول (†): حساب مؤشرستو كاستيك والتباين لسهم أملاك للتمويل ش.م.ع

\begin{tabular}{|c|c|c|c|c|c|c|c|c|c|c|}
\hline \multicolumn{5}{|c|}{ حساب الثباين لعائد سهم مصرف عجمان ش.م.ع } & \multicolumn{6}{|c|}{ النياتات الكاصة لحساب مؤشر ستوكاستيك نسهم مصرف } \\
\hline 10 & 9 & 8 & 7 & 6 & 5 & 4 & 3 & 2 & 1 & العمود \\
\hline 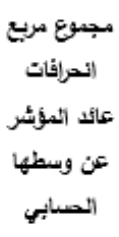 & عربع انحرافات & 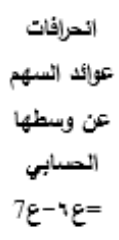 & المعابر & 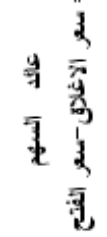 & سإِعلاج & سعر & سعر & الفثر & التاريغ & $\Xi$ \\
\hline 0.000006 & -0.002429 & 0.002714 & 0.000286 & 0.003 & 0.32 & 0.327 & 0.337 & 0.332 & $8 / 8 / 2019$ & $\overline{1}$ \\
\hline 0.000000 & 0.000571 & -0.000286 & 0.000286 & 0 & 0.329 & 0.325 & 0.333 & 0.329 & $7 / 8 / 22019$ & 2 \\
\hline 0.000029 & -0.005429 & 0.005714 & 0.000286 & 0.006 & 0.321 & 0.314 & 0.328 & 0.315 & $6 / 8 / 2019$ & 3 \\
\hline 0.000012 & -0.003429 & 0.003714 & 0.000286 & 0.004 & 0.325 & 0.31 & 0.325 & 0.321 & $5 / 8 / 2019$ & 4 \\
\hline 0.000134 & 0.011571 & -0.011286 & 0.000286 & -0.011 & 0.321 & 0.321 & 0.332 & 0.332 & $4 / 8 / 2019$ & 5 \\
\hline 0.000092 & 0.009571 & -0.009286 & 0.000286 & -0.009 & 0.331 & 0.33 & 0.34 & 0.34 & $1 / 8 / 2019$ & 6 \\
\hline 0.000112 & 0.010571 & -0.010286 & 0.000286 & -0.01 & 0.338 & 0.338 & 0.351 & 0.348 & $31 / 7 / 2019$ & 7 \\
\hline 0.000002 & 0.001571 & -0.001286 & 0.000286 & -0.001 & 0.343 & 0.34 & 0.349 & 0.344 & $30 / 7 / 2019$ & 8 \\
\hline 0.000089 & -0.009429 & 0.009714 & 0.000286 & 0.01 & 0.344 & 0.332 & 0.344 & 0.334 & $29 / 7 / 2019$ & 9 \\
\hline 0.000007 & 0.002571 & -0.002286 & 0.000286 & -0.002 & 0.336 & 0.335 & 0.345 & 0.338 & $28 / 7 / 2019$ & 10 \\
\hline 0.000029 & -0.005429 & 0.005714 & 0.000286 & 0.006 & 0.338 & 0.332 & 0.352 & 0.332 & $25 / 7 / 2019$ & 11 \\
\hline 0.000000 & -0.000429 & 0.000714 & 0.000286 & 0.001 & 0.331 & 0.325 & 0.332 & 0.33 & $24 / 7 / 2019$ & 12 \\
\hline 0.000000 & 0.000571 & -0.000286 & 0.000286 & 0 & 0.33 & 0.325 & 0.334 & 0.33 & $23 / 72019$ & 13 \\
\hline 0.000006 & -0.002429 & 0.002714 & 0.000286 & 0.003 & 0.335 & 0.327 & 0.337 & 0.332 & $8 / 8 / 2019$ & 14 \\
\hline 0.000521 & & & ألمجموع & 0.001 & & & & & & المجموع \\
\hline 0.000037 & & & ألثباين & 0.000071 & & & & & سابي & الثوبط الد \\
\hline
\end{tabular}

المصدر : من إعداد الباحثة بالاعتماد على بيانات المصرف المنشورة في سوق دبي للأوراق المالية

https://marketwatch.dfm.ae

\begin{tabular}{|c|c|c|c|c|c|}
\hline \multirow[b]{2}{*}{ ???!? } & اقل سعر لسهم خلال & - & اخر سعر للسهم خلال & \multirow{2}{*}{$\begin{array}{c}100 \\
\times\end{array}$} & \multirow{2}{*}{ 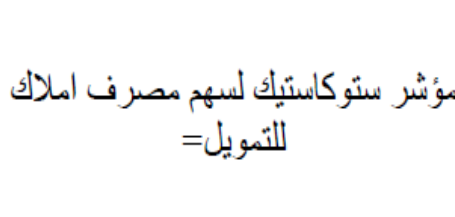 } \\
\hline & اقل سعر لسهم خلال $=$ & - & اعلى سعر للسهم خلال & & \\
\hline & 0.31 & - & 0.335 & 100 & مؤشر ستوكاستيك لسهم مصرف املاك \\
\hline & 0.31 & - & 0.352 & $x$ & $=$ \\
\hline
\end{tabular}

يبين الجدول (7) عملية احتساب مؤشر ستوكاستيك وتباين أملاك للتمويل ش.م.ع التي يحتاج اليها

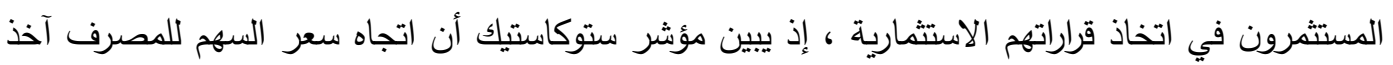

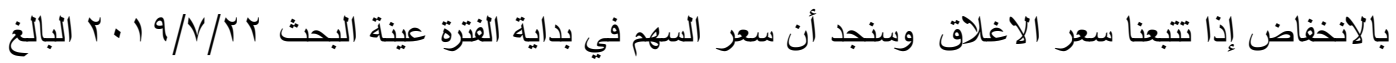

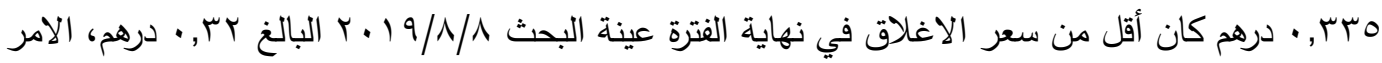
الذي يعطي مؤشراً عن أن اتجاه سعر السهم في المستقبل سوف ينخفض ، وبلغت نتيجة مؤشر ستوكاستيك

TANMIYAT AL-RAFIDAIN (P-ISSN: 1609-591X; E-ISSN: 2664-276X) تنمية الرافدين 


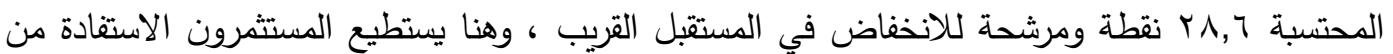

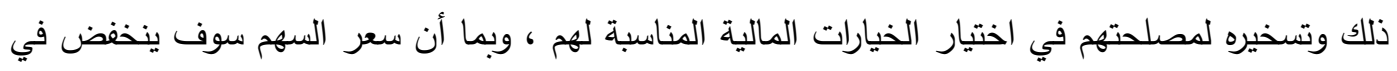

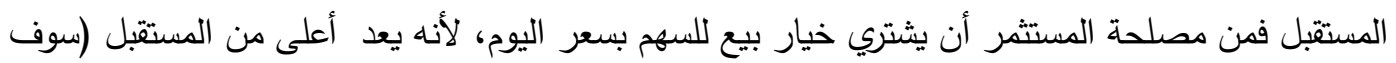

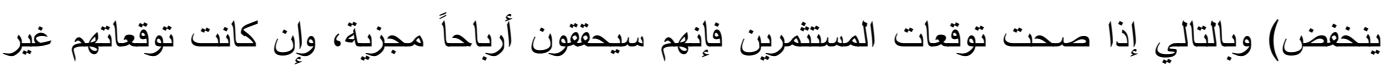

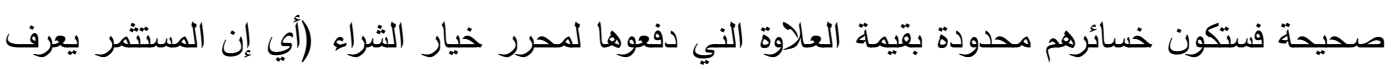

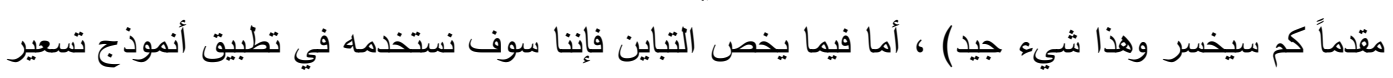

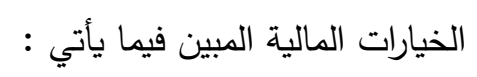
احتساب سعر حق اختيار شراء مؤشر سوق العراق للأوراق المالية باستخدام أنموذج بلاك- شولز

$\mathrm{d} 1=\left(\ln (0.32 / 0.335)+\left(0.03+0.000037^{\wedge} 2 / 2\right) * 0.5 / 0.000037^{*} * 0.5^{\wedge} \mathbf{0 . 5}=-1177.60 \mathrm{Nd} 1=\right.$ وكما يأتي: =00 0.00 d2 $=-1177.60-0.000037^{*} * 0.5^{\wedge} 0.5=-1177.60-0.0439820=-1177.60$

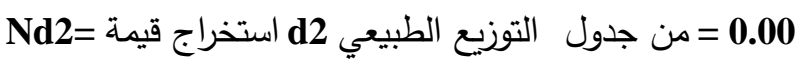

$\mathrm{V}=\mathrm{s} * \mathrm{nd1-x}$ *exp(-t*r)*nd2

$\mathbf{V}=\mathbf{0 . 3 2} * \mathbf{0 . 0 0 - 0 . 3 3 5} * 2.7183^{-0.03 * 0.5 * \mathbf{0 . 0 0}}$

V=0.00 درهم سعر خيار البيع الواحد

وبما أن المستثمر أصبح باستطاعته احتساب قيمة الخيار المالي البالغة ه.., • درهم فإنه بذلك قام

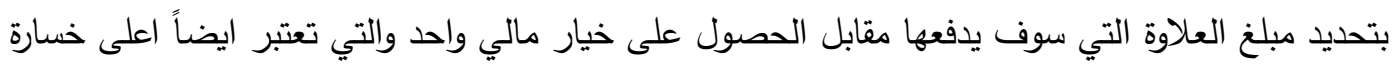

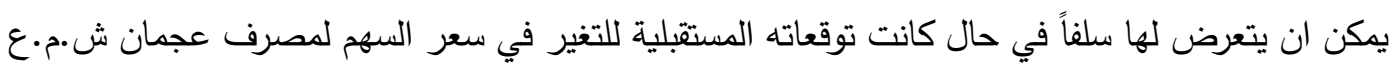
خاطئة ، أما لو صحت توقعات المستثر فإنه سيحقق أرباحاً ، وبما أننا نتعامل مع المستقبل، فيمكن أن نقوم بعمل عدة سيناريوهات للتغير في سعر السهم لبيان حجم الأرباح في كل حالة وكما مبين فيما يأتي :

جدول (V): سيناريوهات تغير سعر سهم أملاك للتمويل ش.م.ع

\begin{tabular}{|c|c|c|c|c|c|c|c|c|c|c|c|c|}
\hline والثربع إلى المبلئ الكسارة & المستثمر & صافي الزبتح & صافي الربح او الكسارة & & العلاوة & & إنيمة & & التنفيذ & & ستمر & $ت$ \\
\hline 0 & $\overline{0}$ & $\overline{0}$ & $\overline{0}$ & $=$ & 0 & - & 0 & $=$ & 0 & - & $\overline{0}$ & 1 \\
\hline 0 & 0 & 0 & 0 & $=$ & 0 & - & 0 & $=$ & 0 & - & 0 & 2 \\
\hline 0 & 0 & 0 & 0 & $=$ & 0 & - & 0 & $=$ & 0 & - & 0 & 3 \\
\hline
\end{tabular}

المصدر : من اعداد بالاعتماد على جدول (؟)

يبين الجدول (V) أن قيمة الخيار المالي تساوي · لذلك لن يتم الاتفاق بين كل من المستثمر والمحرر بسبب عدم الجدوى الاقتصادية. 
جدول (^): حساب مؤشر ستوكاستيك والتباين لسهم مجموعة جي اف اتش المالية ش.م.ب

\begin{tabular}{|c|c|c|c|c|c|c|c|c|c|c|}
\hline \multicolumn{5}{|c|}{ حساب التباين لعائد سهم مصرف عجمان ش.م.ع } & \multicolumn{5}{|c|}{ ألكاصة لحساب مؤشر ستوكاستيك لسهم مصرف عجمان } & \multirow[b]{2}{*}{ العمولة } \\
\hline 10 & 9 & 8 & 7 & 6 & 5 & 4 & 3 & 2 & 1 & \\
\hline انحراقات عائد & 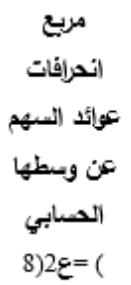 & 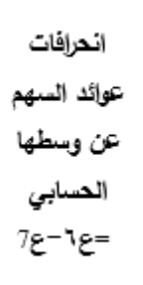 & 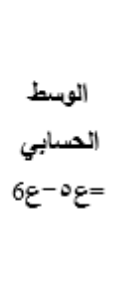 & 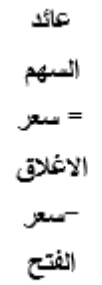 & الإغلاق سعر & 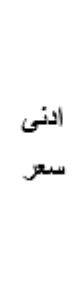 & اعلى - اعز & رتفت & التاريخ & $ت$ \\
\hline $\begin{array}{l}0.000199 \\
0.000000\end{array}$ & $\begin{array}{l}0.014114 \\
0.000114\end{array}$ & $\begin{array}{l}-0.014057 \\
-0.000057\end{array}$ & $\begin{array}{l}0.000057 \\
0.000057\end{array}$ & $\begin{array}{r}-0.0140 \\
0.0000\end{array}$ & $\begin{array}{l}0.916 \\
0.913\end{array}$ & $\begin{array}{l}0.907 \\
0.906\end{array}$ & $\begin{array}{l}0.91 \\
0.92\end{array}$ & $\begin{array}{r}0.91 \\
0.913\end{array}$ & $\begin{array}{r}8 / 8 / 2019 \\
7 / 8 / 22019\end{array}$ & 1 \\
\hline 0.000395 & -0.019886 & 0.019943 & 0.000057 & 0.0200 & 0.91 & 0.886 & 0.915 & 0.89 & $6 / 8 / 2019$ & 3 \\
\hline 0.000102 & 0.010114 & -0.010057 & 0.000057 & -0.0100 & 0.9 & 0.882 & 0.91 & 0.91 & $5 / 8 / 2019$ & $\begin{array}{l}4 \\
5\end{array}$ \\
\hline $\begin{array}{l}0.000051 \\
0.000051\end{array}$ & $\begin{array}{l}0.007114 \\
0.007114\end{array}$ & $\begin{array}{l}-0.007057 \\
-0.007057\end{array}$ & 0.000057 & -0.0070 & 0.911 & 0.905 & 0.921 & 0.918 & $4 / 8 / 2019$ & $\begin{array}{l}5 \\
6\end{array}$ \\
\hline 0.000790 & 0.028114 & $\begin{array}{l}-0.007057 \\
-0.028057\end{array}$ & $\begin{array}{l}0.000057 \\
0.000057\end{array}$ & $\begin{array}{l}-0.0070 \\
-0.0280\end{array}$ & $\begin{array}{l}0.924 \\
0.939\end{array}$ & $\begin{array}{r}0.922 \\
0.93\end{array}$ & 0.939 & $\begin{array}{l}0.931 \\
0.967\end{array}$ & $\begin{array}{r}1 / 8 / 2019 \\
31 / 7 / 2019\end{array}$ & 0 \\
\hline 0.000008 & -0.002886 & 0.002943 & 0.000057 & 0.0030 & 0.96 & 0.954 & 0.97 & 0.957 & $30 / 7 / 2019$ & 8 \\
\hline 0.000571 & -0.023886 & 0.023943 & 0.000057 & 0.0240 & 0.955 & 0.931 & 0.956 & 0.931 & $29 / 7 / 2019$ & 9 \\
\hline 0.000015 & -0.003886 & 0.003943 & 0.000057 & 0.0040 & 0.934 & 0.927 & 0.945 & 0.93 & $28 / 7 / 2019$ & 10 \\
\hline 0.000037 & 0.006114 & -0.006057 & 0.000057 & -0.0060 & 0.93 & 0.927 & 0.947 & 0.936 & $25 / 7 / 2019$ & 11 \\
\hline 0.000619 & -0.024886 & 0.024943 & 0.000057 & 0.0250 & 0.933 & 0.908 & 0.934 & 0.908 & $24 / 7 / 2019$ & 12 \\
\hline 0.000026 & 0.005114 & -0.005057 & 0.000057 & -0.00 & 0.903 & 0.901 & 0.909 & 0.908 & 23/72019 & 13 \\
\hline 0.000079 & -0.008886 & 0.008943 & 0.000057 & 0.0090 & 0.899 & 0.89 & 0.905 & 0.89 & $22 / 7 / 2019$ & 14 \\
\hline 0.002944 & & & المجموع & 0.0080 & & & & & & المجموع \\
\hline 0.000210 & & & التباين & 0.0006 & & & & & سابي & الوسد \\
\hline
\end{tabular}

المصدر: من إعداد الباحثة بالاعتماد على بيانات المصرف المنشورة في سوق دبي للأوراق المالية https://marketwatch.dfm.ae

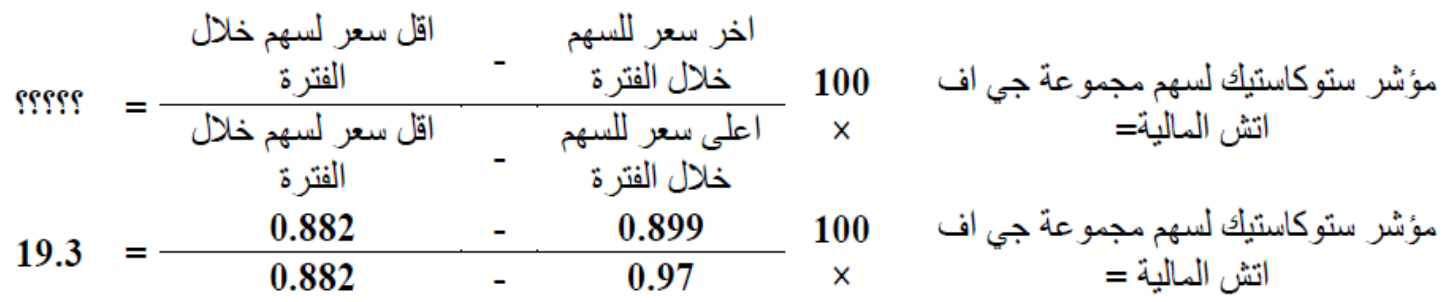

يبين الجدول (^) عملية احتساب مؤشر ستوكاستيك وتباين مجموعة جي اف اتش المالية ش.م.ب التي يحتاج اليها المستثرون في اتخاذ قراراتهم الاستثارية ، إذ يبين مؤشر ستوكاستيك أن اتجاه سعر السهم للمصرف آخذ بالارتفاع اذا تتبعنا سعر الاغلاق وسنجد أن سعر السهم في بداية الفترة عينة البحث

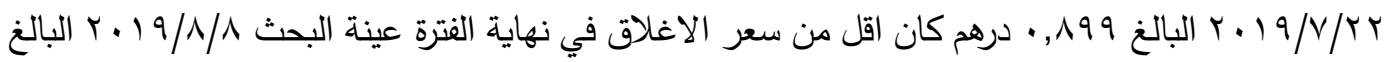
ج ا(9, • درهم الامر الذي يعطي مؤشراً عن أن اتجاه سعر السهم في المستقبل سوف يرتفع ، وبلغت نتيجة مؤشر ستوكاستيك المحتسبة r, 1 نقطة ومرشحة للارتفاع في المستقبل القريب ، وهنا يستطيع المستثرون 
الاستفادة من ذلك وتسخيره لمصلحتهم في اختيار الخيارات المالية المناسبة لهم ، وبما أن سعر السهم سوف يرتفع في المستقبل فمن مصلحة المستثر أن يشتري خيار شراء للسهم بسعر اليوم كونه يعد أقل من المستقبل

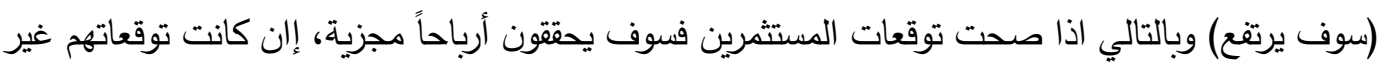

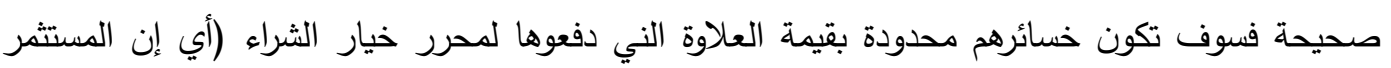
يعرف مقدماً كم سوف يخسر وهذا شيء جيد) ، أما فيما يخص التباين فإننا سوف نستخدمه في تطبيق

$$
\text { أنموذج تسعير الخيارات المالية المبين ادناه : }
$$

d1=(ln(0.916/0.899)+(0.03+0.000210^2/2)*0.5/0.000210*0.5^0.5=227.17Nd1= استخراج قيمة d1 = 1.00

d2=227.17- $0.000210 * 0.5^{\wedge} 0.5=227.17-1.484924=227.17$

Nd2=1.00 $=1$ من جدول التوزيع الطبيعي d2 استخراج قيمة

$\mathrm{V}=\mathrm{s}^{*} \mathrm{nd1}-\mathrm{x} * \exp (-\mathrm{t} * \mathrm{r}) * \mathrm{nd} 2$

$\mathrm{V}=\mathbf{0 . 9 1 6} * \mathbf{1 . 0} \mathbf{0 . 0 . 8 9 9} * 2.7183^{-0.03 * 0.5 * 1.00}$

V=0.03 درهم سعر خيار الثراء الواحد

وبما أن المستثمر اصبح باستطاعته احتساب قيمة الخيار المالي البالغة ه.., • درهم فإنه بذلك قام بتحديد مبلغ العلاوة التي سوف يدفعها مقابل الحصول على خيار مالي واحد والتي تعتبر ايضاً أعلى خسارة

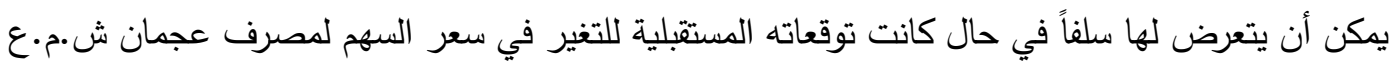

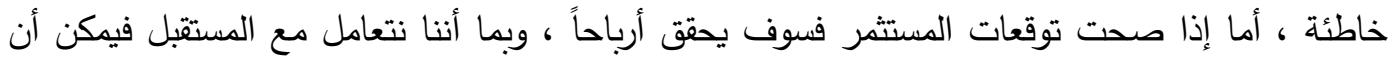
نقوم بعمل عدة سيناريوهات للتغير في سعر السهم لبيان حجم الأرباح في كل حالة وكما مبين فيما يأتي : جدول (9): سيناريوهات تغير سعر سهم مجموعة جي اف اتش المالية ش.م.ب

\begin{tabular}{|c|c|c|c|c|c|c|c|c|c|c|c|c|}
\hline نالمبة الكسارة & المستئمر & او المسافي الريح & صافي الزبرع او & & العلاوة & & قالكيار حق & & ستثفيذ & & المتوقع & $ت$ \\
\hline $100 \%$ & لاينفذ & 0.03 & $0.03-$ & $=$ & 0.03 & - & 0 & $=$ & 0.899 & - & 0.1 & 1 \\
\hline $0 \%$ & نقطة & 0 & 0 & $=$ & 0.03 & - & 0.03 & $=$ & 0.899 & - & 0.929 & 2 \\
\hline $236 \%$ & ينفذ & $0.071-$ & 0.071 & $=$ & 0.03 & - & 0.101 & $=$ & 0899 & - & 1 & 3 \\
\hline
\end{tabular}

المصدر : من اعداد بالاعتماد على جدول (^).

تبين من خلا تحليل مؤشر ستوكاستيك أن سعر السهم لمجموعة (جي اف اتش المالية ش.م.ب) سوف يرتقع في المستقبل لذلك بمقدور المستثر شراء خيار شراء ، ويبين الجدول (9) ثلاثثة سيناريوهات للتغير في سعر السهم لبيان حجم الأرباح والخسائر للمستثمرين مشتري خيار الثراء ومحرري خيار الثراء

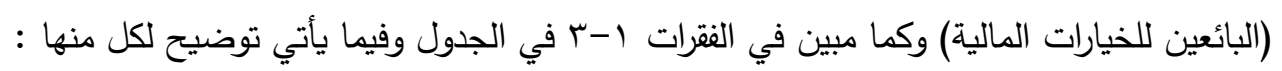

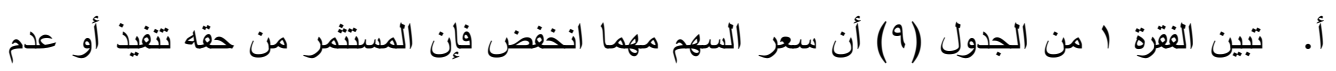
تتفيذ خيار الشراء ، وبما الن المستثمر اتقق على شراء السهم من المحرر بـ 199人, • درهم، وإن 
سعر السهم الآن ا, • درهم فإن المستثمر سيقارن بينهما فإن وجد أن تتفيذ العقد فيه ضرر كبير

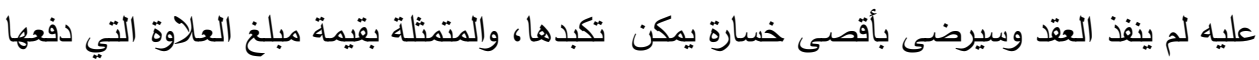

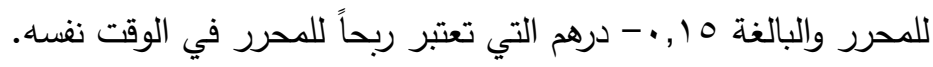

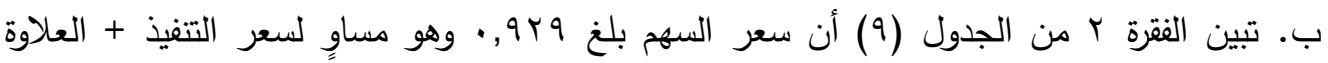

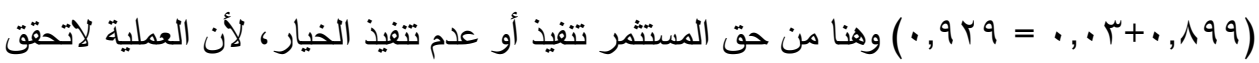

$$
\text { له لاربحاً ولا خسارة (نقطة التعادل). }
$$

ج. تبين الفقرة r من الجدول (9) أن سعر السهم ارتفع كما توقع المستثمر فانه سوف يحقق أرباحاً

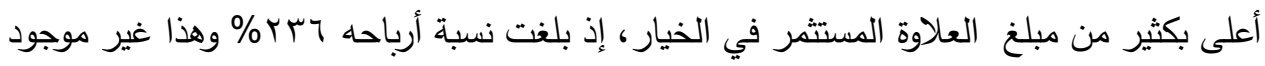

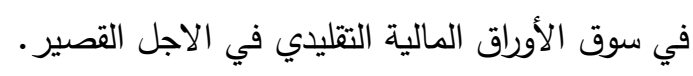

د. إذا كان المستثمر يستثر في السوق التقليدي فإنه يستطيع تسخير الخيارات المالية لتقليل الخسائر فيه من خلال اتخاذ مركز استثماري معاكس في سوق الخيارات المالية وبالتالي فان مايخسره في

\begin{tabular}{|c|c|c|c|c|c|c|c|c|c|c|}
\hline \multicolumn{5}{|c|}{ صناب التباين نعائد سهم مصرأ عجمان ش.م.ع } & \multicolumn{6}{|c|}{ أثيائات الخاصة لحساب مؤئر ستوكاسثيك لسهم مصرئ عجمان } \\
\hline 10 & 9 & 8 & 7 & 6 & 5 & 4 & 3 & 2 & 1 & العمود \\
\hline انمرافئت عائد & 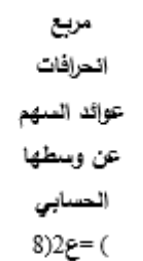 & 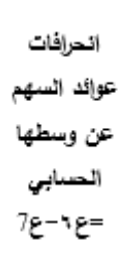 & 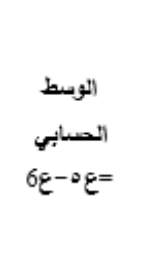 & 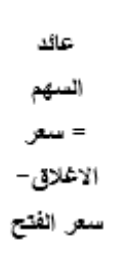 & الإعلاد سعر & 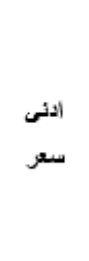 & 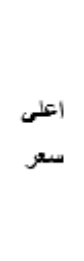 & سلفثح & التباريغ & ت \\
\hline 0.000024 & -0.004857 & 0.003429 & -0.001429 & 0.0020 & 0.247 & 0.245 & 0.254 & 0.245 & $8 / 8 / 2019$ & 1 \\
\hline 0.000141 & -0.011857 & 0.010429 & -0.001429 & 0.0090 & 0.244 & 0.235 & 0.25 & 0.235 & $7 / 8 / 22019$ & 2 \\
\hline $\begin{array}{l}0.000008 \\
0.000261\end{array}$ & $\begin{array}{c}-0.002857 \\
0.016143\end{array}$ & $\begin{array}{r}0.001429 \\
-0.017571\end{array}$ & $\begin{array}{l}-0.001429 \\
-0.001429\end{array}$ & $\begin{array}{c}0.0000 \\
-0.0190\end{array}$ & $\begin{array}{l}0.237 \\
0.242\end{array}$ & $\begin{array}{l}0.234 \\
0.237\end{array}$ & 0.239 & 0.237 & $\begin{array}{l}6 / 8 / 2019 \\
5 / 8 / 2019\end{array}$ & 3 \\
\hline 0.000005 & 0.002143 & $\begin{array}{l}-0.017571 \\
-0.003571\end{array}$ & $\begin{array}{l}-0.001429 \\
-0.001429\end{array}$ & $\begin{array}{l}-0.0190 \\
-0.0050\end{array}$ & 0.263 & 0.263 & 0.272 & 0.268 & $4 / 8 / 2019$ & 5 \\
\hline 0.000034 & -0.005857 & 0.004429 & -0.001429 & 0.0030 & 0.265 & 0.262 & 0.274 & 0.262 & $1 / 8 / 2019$ & 6 \\
\hline 0.000005 & 0.002143 & -0.003571 & -0.001429 & -0.0050 & 0.267 & 0.261 & 0.272 & 0.272 & $31 / 7 / 2019$ & 7 \\
\hline 0.000015 & -0.003857 & 0.002429 & -0.001429 & 0.0010 & 0.267 & 0.263 & 0.275 & 0.266 & $30 / 7 / 2019$ & 8 \\
\hline 0.000000 & 0.000143 & -0.001571 & -0.001429 & -0.0030 & 0.262 & 0.262 & 0.267 & 0.265 & $29 / 7 / 2019$ & 9 \\
\hline 0.000062 & -0.007857 & 0.006429 & -0.001429 & 0.0050 & 0.265 & 0.26 & 0.275 & 0.26 & $28 / 7 / 2019$ & 10 \\
\hline 0.000003 & -0.001857 & 0.000429 & -0.001429 & -0.0010 & 0.255 & 0.25 & 0.26 & 0.256 & $25 / 7 / 2019$ & 11 \\
\hline 0.000008 & -0.002857 & 0.001429 & -0.001429 & 0.0000 & 0.26 & 0.251 & 0.265 & 0.26 & $24 / 7 / 2019$ & 12 \\
\hline 0.000084 & 0.009143 & -0.010571 & -0.001429 & -0.0120 & 0.252 & 0.252 & 0.264 & 0.264 & $23 / 72019$ & 13 \\
\hline 0.000062 & -0.007857 & 0.006429 & -0.001429 & 0.0050 & 0.26 & 0.25 & 0.27 & 0.255 & $22 / 7 / 2019$ & 14 \\
\hline 0.000710 & & & المجموع & -0.0200 & & & & & & 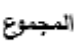 \\
\hline 0.000051 & & & الثباين & -0.0014 & & & & & لاببر & الثوبط (ان \\
\hline
\end{tabular}
السوق التقليدي يكسبه في سوق الخيارات ما يقلل الخطر الذي يتعرض لله في المستقبل.

جدول (· ( ): حساب مؤشر ستوكاستيك والتباين لسهم شركة الإثمار القابضة ش.م.ب

TANMIYAT AL-RAFIDAIN (P-ISSN: 1609-591X; E-ISSN: 2664-276X) تنمية الرافدين 


$$
\begin{aligned}
& \text { مؤشر ستو كاستيك لسهم مصرف } \\
& 62.5 \\
& 0.235 \\
& 0.26 \\
& 0.275
\end{aligned}
$$

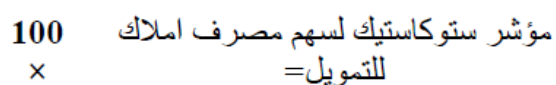

يبين الجدول (• () عملية احتساب مؤشر ستوكاستيك والتباين شركة الإثمار القابضة ش.م.ب التي يحتاج إليها المستثمرون في اتخاذ قراراتهم الاستثمارية ، إذ يبين مؤشر ستوكاستيك أن اتجاه سعر السهم للمصرف آخذ بالانخفاض إذا تتبعنا سعر الاغلاق سوف نجد أن سعر السهم في بداية الفترة عينة البحث البثان

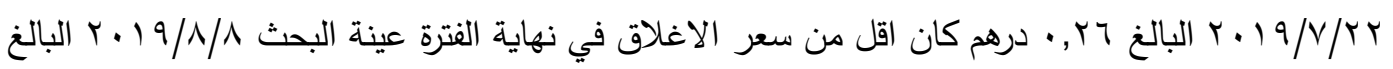

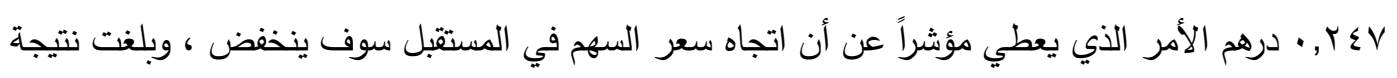

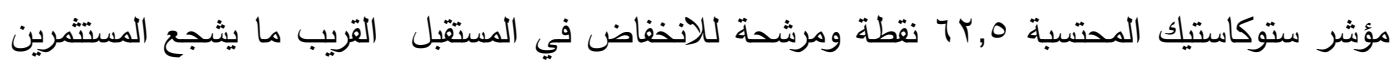
على الاقبال على بيعه ، وهنا يستطيع المستثمرون الاستفادة من ذلك وتسخيره لمصلحتهم في اختيار الخيارات المالية المناسبة لهم ، وبما أن سعر السهم سوف ينخفض في المستئقبل فمن مصلحة المستثمر أن يشتري خيار بيع السهم بسعر اليوم كونه يعد أعلى من المستقبل (سوف ينخفض) وبالتالي إذا صحت توقعات ستون المستثرين فإنهم سوف يحققون أرباحاً مجزية وإن كانت توقعاتهم غير صحيحة سوف تكون خسائرهم محدودة بقيمة العلاوة التي دفعوها لمحرر خيار الشراء (أي إن المستثر يعرف مقدماً كم سوف يخسر وهذا شيء جيد) ، أما فيما يخص التباين فإننا سوف نستخدمه في تطبيق أنموذج تسعير الخيارات المالية المبين ادناه :

$d 1=\left(\ln (0.247 / 0.26)+\left(0.03+0.000051^{\wedge} 2 / 2\right) * 0.5 / 0.000051 * 0.5^{\wedge} 0.5=-1717.38 N d 1=\right.$

d1 0.00

d2=-1717.38- $0.000051^{*} 0.5^{\wedge} \mathbf{0 . 5}=\mathbf{- 1 7 1 7 . 3 8 - 3 . 6 = - 1 7 1 7 . 3 8}$

Nd2=0.00

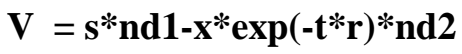

$\mathbf{V}=\mathbf{0 . 2 4 7} * \mathbf{0 . 0 0 - 0 . 2 6} * 2.7183^{-0.03 * 0.5 * \mathbf{0 . 0 0}}$

V=0.00 درهم سعر خيار الشراء الواحد

وبما أن المستثمر اصبح باستطاعته احتساب قيمة الخيار المالي البالغة ه.,. • درهم فإنه بذلك قام

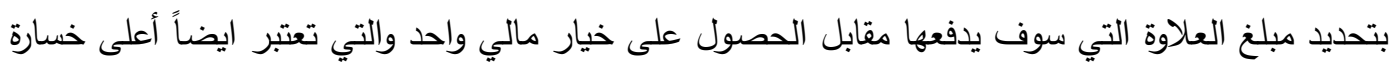

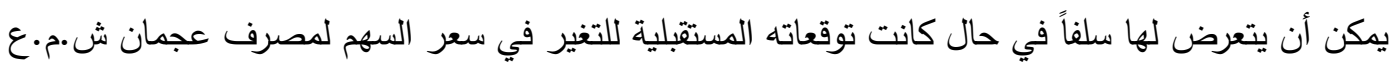

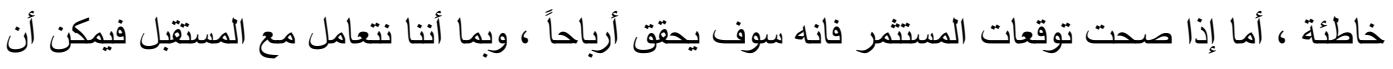
نقوم بعمل عدة سيناريوهات للتغير في سعر السهم لبيان حجم الأرباح في كل حالة وكما مبين فيما يأتي : 
جدول (1 11 ): سيناريوهات شركة الإثمار القابضة ش.م.ب

\begin{tabular}{|c|c|c|c|c|c|c|c|c|c|c|c|c|}
\hline نالئربح إلى المسبلغ & المستئمر & صافي الزربع & صافي الزبح او & & العلاوة & & حقيمة & & التنفيذ & & المتوقع & $ت$ \\
\hline 0 & 0 & 0 & 0 & $=$ & 0 & - & 0 & $=$ & 0 & - & 0 & 1 \\
\hline 0 & 0 & 0 & 0 & $=$ & 0 & - & 0 & $=$ & 0 & - & 0 & 2 \\
\hline 0 & 0 & 0 & 0 & $=$ & 0 & - & 0 & $=$ & 0 & - & 0 & 3 \\
\hline
\end{tabular}

المصدر : من إعداد بالاعتماد على جدول (·) (1).

يبين الجدول (1') أن قيمة الخيار المالي تساوي · لفانه لن يتم الاتفاق بين كل من المستثر

$$
\text { والمحرر بسبب عدم الجدوى الاقتصادية. }
$$

جدول (r ( ): حساب مؤشر ستوكاستيك والتباين لسهم المصرف الخليجي التجاري ش.م.ب

\begin{tabular}{|c|c|c|c|c|c|c|c|c|c|c|}
\hline \multicolumn{5}{|c|}{ حساب التباين لعائد سهم مصرف عجمان ش.م.ع } & \multicolumn{6}{|c|}{ |أبيانات الكاصة لحساب مؤشُر ستوكاستيك لسهم مصرف عجمان } \\
\hline 10 & 9 & 8 & 7 & 6 & 5 & 4 & 3 & 2 & 1 & الثعويد \\
\hline انحراقات عائد & 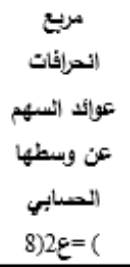 & 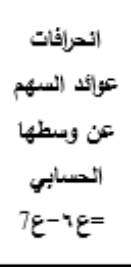 & 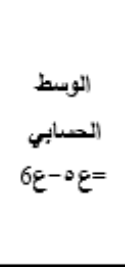 & 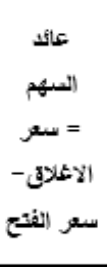 & الإعلاج سعر & 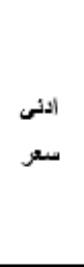 & 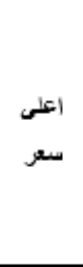 & الفثح & التاريخ & ت \\
\hline 0.449474 & 0.670429 & -0.323714 & 0.346714 & 0.0230 & 0.57 & 0.547 & 0.57 & 0.547 & $8 / 8 / 2019$ & 1 \\
\hline 0.454854 & 0.674429 & -0.327714 & 0.346714 & 0.0190 & 0.56 & 0.541 & 0.58 & 0.541 & $7 / 8 / 22019$ & 2 \\
\hline 0.008729 & 0.093429 & 0.253286 & 0.346714 & 0.6000 & 0.6 & 0 & 0 & 0 & 6/8/2019 & 3 \\
\hline 0.452160 & 0.672429 & -0.325714 & 0.346714 & 0.0210 & 0.6 & 0.579 & 0.6 & 0.579 & $5 / 8 / 2019$ & 4 \\
\hline 0.008917 & 0.094429 & 0.252286 & 0.346714 & 0.5990 & 0.599 & 0 & 0 & 0 & 4/8/2019 & 5 \\
\hline 0.405041 & 0.636429 & -0.289714 & 0.346714 & 0.0570 & 0.599 & 0.542 & 0.609 & 0.542 & $1 / 8 / 2019$ & 6 \\
\hline 0.446797 & 0.668429 & -0.321714 & 0.346714 & 0.0250 & 0.58 & 0.555 & 0.58 & 0.555 & $31 / 7 / 2019$ & 7 \\
\hline 0.011757 & 0.108429 & 0.238286 & 0.346714 & 0.5850 & 0.585 & 0 & 0 & 0 & $30 / 7 / 2019$ & 8 \\
\hline 0.480843 & 0.693429 & -0.346714 & 0.346714 & 0.0000 & 0.585 & 0.585 & 0.585 & 0.585 & 29/7/2019 & 9 \\
\hline 0.011757 & 0.108429 & 0.238286 & 0.346714 & 0.5850 & 0.585 & 0 & 0 & 0 & $28 / 7 / 2019$ & 10 \\
\hline 0.011757 & 0.108429 & 0.238286 & 0.346714 & 0.5850 & 0.585 & 0 & 0 & 0 & $25 / 7 / 2019$ & 11 \\
\hline 0.011757 & 0.108429 & 0.238286 & 0.346714 & 0.5850 & 0.585 & 0 & 0 & 0 & 24/7/2019 & 12 \\
\hline 0.011757 & 0.108429 & 0.238286 & 0.346714 & 0.5850 & 0.585 & 0 & 0 & 0 & 23/72019 & 13 \\
\hline 0.011757 & 0.108429 & 0.238286 & 0.346714 & 0.5850 & 0.585 & 0 & 0 & 0 & $22 / 7 / 2019$ & 14 \\
\hline 2.777356 & & & المجموع & 4.8540 & & & & & & (المجموع \\
\hline 0.198383 & & & التباين & 0.3467 & & & & & مابي & |الوسط || \\
\hline
\end{tabular}

المصدر: من اعداد الباحثة بالاعتماد على بيانات المصرف المنشورة في سوق دبي للأوراق المالية

https://marketwatch.dfm.ae

\begin{tabular}{|c|c|c|c|c|c|}
\hline \multirow[b]{2}{*}{ ؟ִ؟؟؟؟ } & اقل سعر لسهم خلال & & اخر سعر للسهم خلال & 100 & مؤشر ستوكاستيك لسهم مصرف الخليجي \\
\hline & اقل سعر لسهم خلال $=$ & - & اعلى سعر اللسهم خلال & $\times$ & ألتجاري = \\
\hline & 0.541 & - & 0.585 & 100 & مؤشر ستو كاستيك لسهم مص \\
\hline & 0.541 & - & 0.609 & $x$ & التجاري = \\
\hline
\end{tabular}

TANMIYAT AL-RAFIDAIN (P-ISSN: 1609-591X; E-ISSN: 2664-276X) تنمية الرافدين 
يبين الجدول (r ( ) عملية احتساب مؤشر ستوكاستيك والتباين لرصرف خليجي التجاري ش.م.ب التي يحتاج إليها المستثمرون في اتخاذ قرارتهم الاستثمارية ، إذ يبين مؤشر ستوكاستيك أن اتجاه سعر السهر للدصرف آخذ بالانخفاض إذا تتبعنا سعر الاغلاق سوف نجد أن سعر السهم في بداية الفترة عينة البحث

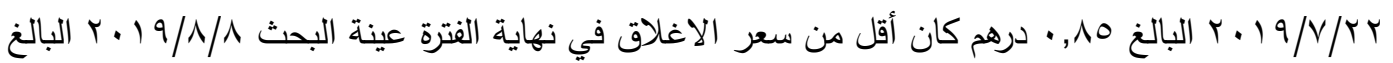
V O V • • درهم الامر الذي يعطي مؤشراً عن اتجاه سعر السهم في المستقبل سوف ينخفض ، وبلغت نتيجة

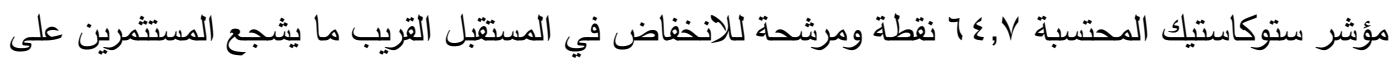
الاقبال على بيعه ، وهنا يستطيع المستثمرون الاستفادة من ذلك وتسخيره لـصلحتهم في اختيار الخيارات المالية المناسبة لهح ، وبما أن سعر السهم سينخفض في الهي المستقبل فمن مصلحة المستثر أن يشتري خيار بيع للسهم بسعر اليوم، لأنه يعد أعلى من المستقبل (سوف ينخفض) وبالتالي إذا صحت توقعات المستثمرين فانهم سوف يحققون أرباحاً مجزية، وإن كانت توقعاتهم غير صحيحة فسوف تكون خسائرهم محدودة بقيمة العلاوة التي دفعوها لمحرر خيار الشراء (أي إن المستثر يعرف مقدماً كم سوف يخسر ، وهذا شيء جيد) ، أما فيما يخص التباين فإننا سوف نستخدمه في تطبيق أنموذج تسعير الخيارات المالية المبين ادناه :

d1 $=\left(\ln (0.57 / 0.585)+(0.03+0.198383 \wedge 2 / 2) * 0.5 / 0.198383 * 0.5^{\wedge} 0.5=-0.01 N d 1=\right.$ (ستخراج d1 0.50 d2=-0.01- $0.198383^{*} 0.5^{\wedge} \mathbf{0 . 5}=\mathbf{- 0 . 0 1 - 0 . 1 4 = - 0 . 1 5}$

Nd2=0.44 = من جدول التوزيع الطبيعي d2 استخراج قيمة

$\mathrm{V}=\mathrm{s} * \mathrm{nd1}-\mathrm{x} * \exp (-\mathrm{t} * \mathbf{r}) * \mathrm{nd} 2$

$\mathbf{V}=\mathbf{0 . 5 7} * \mathbf{0 . 5 0 - 0 . 5 8 5} * 2.7183^{-0.03 * 0.5 * \mathbf{0 . 4 4}}$

V=0.029 درهم سعر خيار البيع الواحد

وبما أن المستثر أصبح باستطاعته احتساب قيمة الخيار المالي البالغة ه.., • درهم فإنه بذلك قام بتحديد مبلغ العلاوة التي سوف يدفعها مقابل الحصول على خيار مالي واحد والتي تعتبر ايضاً اعلى خسارة

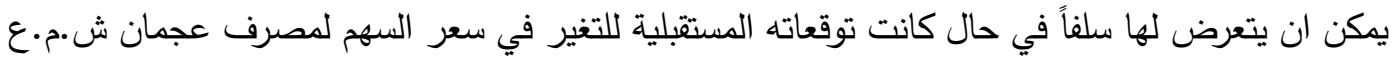

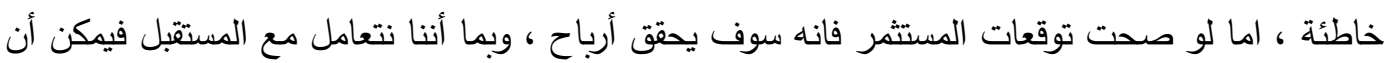
نقوم بعمل عدة سيناريوهات للتغير في سعر السهم لبيان حجم الأرباح في كل حالة وكما مبين ادناه : 


\begin{tabular}{|c|c|c|c|c|c|c|c|c|c|c|c|c|}
\hline نسبة الكسارة & المستئر & لاو الكسارة الربع & صافي الزبرح او & & مبلخ العلاوة & & الكيار حق & & ستنفيذ & & المتوقع & $ت$ \\
\hline $193 \%$ & ينذة & $0.056-$ & 0.056 & $=$ & 0.029 & - & 0.085 & $=$ & 0.585 & - & 0.1 & 1 \\
\hline $0 \%$ & النعادل & 0 & 0 & $=$ & 0.029 & - & 0.029 & $=$ & 0.585 & - & 0.614 & 2 \\
\hline $100 \%$ & لاينئذ & 0.029 & 0.029 & $=$ & 0.029 & - & 0 & $=$ & 0.585 & - & 1 & 3 \\
\hline
\end{tabular}

المصدر : من اعداد بالاعتماد على جدول (r (1).

تبين من خلال تحليل مؤشر ستوكاستيك أن سعر السهم لهصرف الخليج التجاري سوف يرتفع في

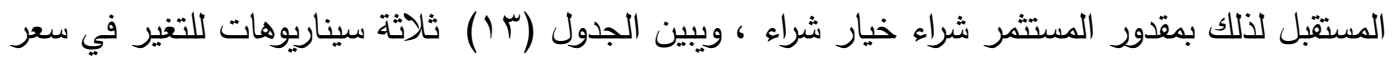
السهم لبيان حجم الأرباح والخسائر للمستثمرين مشتري خيار الشراء ومحرري خيار الثراء (البائعين

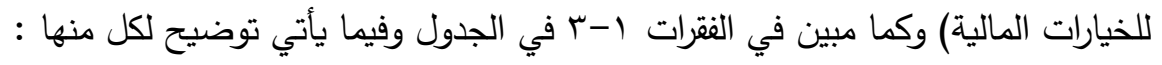

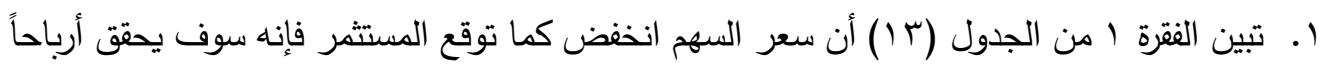

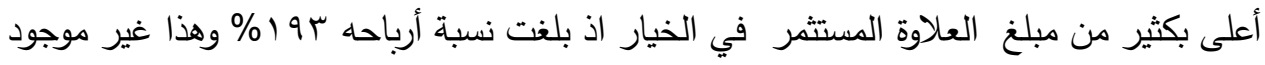

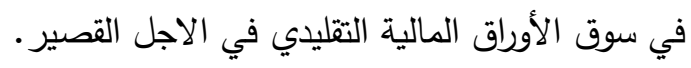

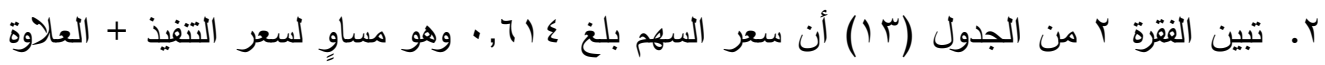

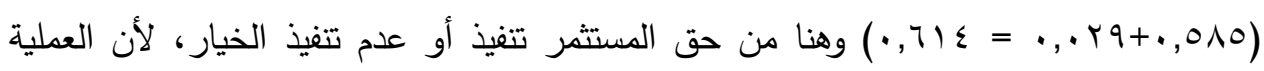
لاتحقق له لاربحاً ولاخسارة (نقطة التعادل).

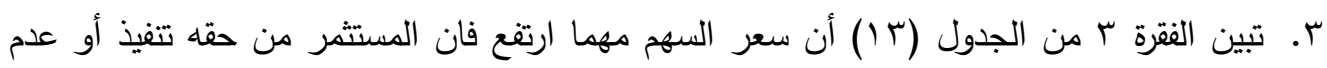

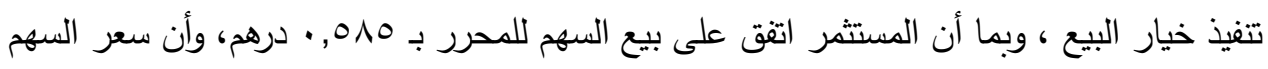

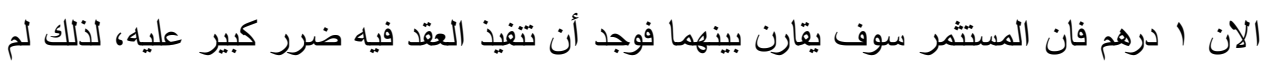
ينفذ العقد ورضي بأقصى خسارة يمكن أن يتكبدها، والمتمثلة بقيمة مبلغ العلاوة التي دفعها للمحرر

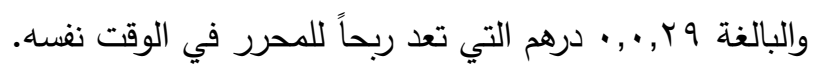

ع. إذا كان المستثمر يستثر في السوق التقليدي فانه يستطيع تسخير الخيارات المالية لتقليل الخسائر

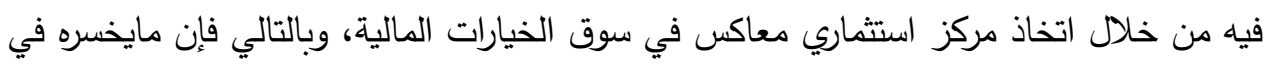
السوق التقليدي يكسبه في سوق الخيارات ما يقلل الخطر الذي يتعرض له له في المستقبل. 
جدول (ع 1): حساب مؤشر ستوكاستيك والتباين لسهم مصرف السلام - البحرين

\begin{tabular}{|c|c|c|c|c|c|c|c|c|c|c|}
\hline \multicolumn{5}{|c|}{ حساب التباين لعائد سهم مصزف عجمان ش.م.ع } & \multicolumn{6}{|c|}{ البيانات الكاصة لحساب مؤئر ستوكاستيك لسهم مصرف } \\
\hline 10 & 9 & 8 & 7 & 6 & 5 & 4 & 3 & 2 & 1 & العموئ \\
\hline أحمرافات عائد & 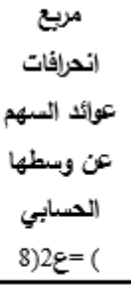 & 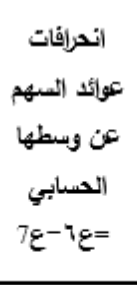 & 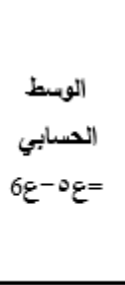 & 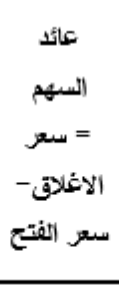 & الإغلاق سعر & 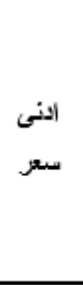 & سعر & سلفتع & 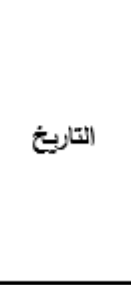 & $ت$ \\
\hline $\begin{array}{l}0.000064 \\
0.000081\end{array}$ & $\begin{array}{l}0.008000 \\
0.009000\end{array}$ & $\begin{array}{l}-0.007000 \\
-0.008000\end{array}$ & $\begin{array}{l}0.001000 \\
0.001000\end{array}$ & $\begin{array}{l}-0.0060 \\
-0.0070\end{array}$ & $\begin{array}{r}0.841 \\
0.84\end{array}$ & $\begin{array}{l}0.84 \\
0.84\end{array}$ & $\begin{array}{r}0.87 \\
0.848\end{array}$ & $\begin{array}{l}0.847 \\
0.847\end{array}$ & $\begin{array}{r}8 / 8 / 2019 \\
7 / 8 / 22019\end{array}$ & 1 \\
\hline 0.000100 & -0.010000 & 0.011000 & 0.001000 & 0.0120 & 0.842 & 0.83 & 0.845 & 0.83 & $6 / 8 / 2019$ & 3 \\
\hline 0.000144 & 0.012000 & -0.011000 & 0.001000 & -0.0100 & 0.83 & 0.83 & 0.842 & 0.84 & $5 / 8 / 2019$ & 4 \\
\hline 0.000001 & 0.001000 & 0.000000 & 0.001000 & 0.0010 & 0.851 & 0.841 & 0.851 & 0.85 & 4/8/2019 & 5 \\
\hline 0.000121 & 0.011000 & -0.010000 & 0.001000 & -0.0090 & 0.86 & 0.86 & 0.88 & 0.869 & $1 / 8 / 2019$ & 6 \\
\hline 0.000001 & 0.001000 & 0.000000 & 0.001000 & 0.0010 & 0.87 & 0.86 & 0.875 & 0.869 & $31 / 7 / 2019$ & 7 \\
\hline 0.000049 & -0.007000 & 0.008000 & 0.001000 & 0.0090 & 0.869 & 0.86 & 0.87 & 0.86 & $30 / 7 / 2019$ & 8 \\
\hline 0.000004 & 0.002000 & -0.001000 & 0.001000 & 0.0000 & 0.86 & 0.851 & 0.869 & 0.86 & 29/7/2019 & 9 \\
\hline 0.000289 & -0.017000 & 0.018000 & 0.001000 & 0.0190 & 0.869 & 0.85 & 0.875 & 0.85 & 28/7/2019 & 10 \\
\hline 0.000400 & 0.020000 & -0.019000 & 0.001000 & -0.0180 & 0.85 & 0.85 & 0.868 & 0.868 & $25 / 7 / 2019$ & 11 \\
\hline 0.000100 & -0.010000 & 0.011000 & 0.001000 & 0.0120 & 0.857 & 0.833 & 0.857 & 0.845 & $24 / 7 / 2019$ & 12 \\
\hline 0.000064 & -0.008000 & 0.009000 & 0.001000 & 0.0100 & 0.845 & 0.831 & 0.845 & 0.835 & 23/72019 & 13 \\
\hline 0.000004 & 0.002000 & -0.001000 & 0.001000 & 0.0000 & 0.845 & 0.845 & 0.845 & 0.845 & $22 / 7 / 2019$ & 14 \\
\hline 0.001422 & & & المجمقع & 0.0140 & & & & & & المجموع \\
\hline 0.000102 & & & الثباين & 0.0010 & & & & & & الثوبط \\
\hline
\end{tabular}

المصدر : من اعداد الباحثة بالاعتماد على بيانات المصرف المنشورة في سوق دبي للأوراق المالية https://marketwatch.dfm.ae

\begin{tabular}{|c|c|c|c|c|c|}
\hline \multirow{2}{*}{ 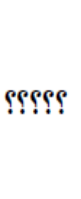 } & اقل سعر لسهم خلال & - & اخر سعر للسهم خلال & 100 & \multirow{2}{*}{ مؤُشر سنوكاستيك لسهم مصرف السلام - } \\
\hline & اقل سعر لسهم خلال & - & اعلى سعر للسهم خلال & $x$ & \\
\hline \multirow{2}{*}{33.3} & 0.83 & - & 0.845 & 100 & مؤشر ستوكاستيك لسهم مصرف السلام - \\
\hline & 0.83 & - & 0.875 & $x$ & البحرين= \\
\hline
\end{tabular}

يبين الجدول (ء () عملية احتساب مؤشر ستوكاستيك والتباين لمصرف السلام - البحرين التي يحتاج إليها المستثرون في اتخاذ قراراتهم الاستثمارية ، إذ يبين مؤشر ستوكاستيك أن اتجاه سعر السهم للمصرف

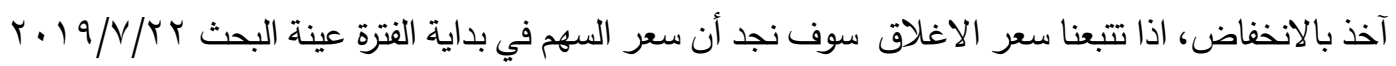

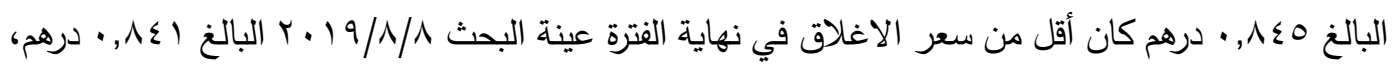
الامر الذي يعطي مؤشراً عن اتجاه سعر السهم في المستقبل سوف ينخفض ، وبلغت نتيجة مؤشر ستوكاستيك المحتسبة المحسوبة ب,س نقطة ومرشحة للانخفاض في المستقبل القريب ما يشجع المستثمرين على الاقبال على بيعه ، وهنا يستطيع المستثرين الاستفادة من ذلك وتسخيره لمصلحتهم في اختيار الخيارات المالية 
المناسبة لهم ، وبما أن سعر السهح سوف ينخفض في المستقبل فمن مصلحة المستثر أن يشتري خيار بيع

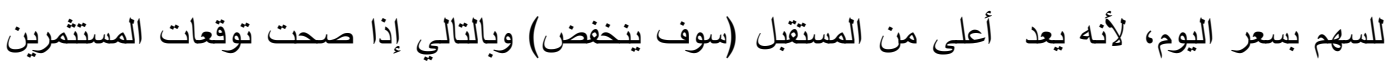
فانهم سوف يحققون أرباحاً مجزية، وإن كانت توقعاتهم غير صحيحة سوف تكون خسائرهم محدودة بقيمة العلاوة الني دفعوها لمحرر خيار الثراء (إي إن المستثر يعرف مقدماً كم سوف يخسر ، وهذا شيء فئ جيد) ، أما فيما يخص التباين فننا سوف نستخدمه في تطبيق أنموذج تسعير الخيارات المالية المبين ادناه :

d1 $=\left(\ln (\mathbf{0 . 8 4 1} / \mathbf{0 . 8 4 5})+\left(0.03+0.000102^{\wedge} 2 / 2\right) * 0.5 / 0.000102^{*} \mathbf{0 . 5} \mathbf{5}^{\wedge} 0.5=142.18 \mathrm{Nd} 1=\right.$

= 1.00

d2=142.18- $0.000102 * 0.5^{\wedge} 0.5=142.18-0.000102=142.18$

Nd2= 1.00

$\mathrm{V}=\mathrm{s} * \mathrm{nd1-x} \exp (-\mathrm{t} * \mathbf{r}) * \mathrm{nd} 2$

$\mathrm{V}=\mathbf{0 . 8 4 1} * \mathbf{1 . 0 0 - 0 . 8 4 5} * 2.7183^{-0.03 * 0.5 * 1.00}$

درهم سعر خيار البيع الواحد V=0.085

وبما أن المستثمر اصبح باستطاعته حساب قيمة الخيار المالي البالغة ه.., درهم، فإنه بذلك قام

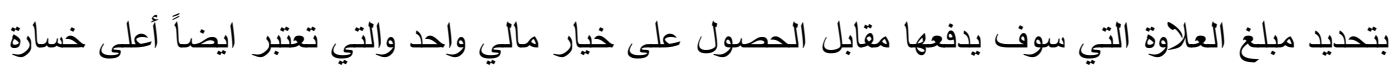

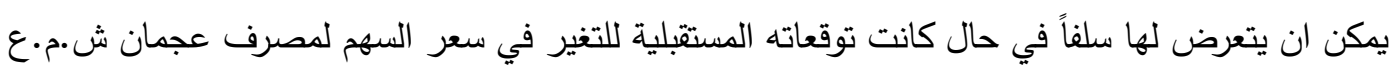
خاطئة، أما إذا صحت توقعات المستثر فسوف يحقق أرباحاً ، وبما أننا نتعامل مع المستقبل فيمكن أن نقوم بعمل عدة سيناريوهات للتغير في سعر السهم لبيان حجم الأرباح في كل حالة وكما مبين فيما يأتي :

جدول (0 1): سيناريوهات تغير سعر سهم السلام - البحرين

\begin{tabular}{|c|c|c|c|c|c|c|c|c|c|c|c|c|}
\hline 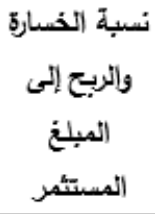 & المستئمر & اللمبح افي & 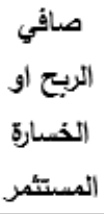 & & العلاوة & & حلى حيمة & & ستبن & & المتوقع & $ت$ \\
\hline $270 \%$ & ينفذ & $0.23-$ & 0.23 & $=$ & 0.085 & - & 0.145 & $=$ & 0.845 & - & 0.1 & 1 \\
\hline $0 \%$ & التعادل & 0 & 0 & $=$ & 0.085 & - & 0.085 & $=$ & 0.845 & - & 0.93 & 2 \\
\hline $100 \%$ & لاينفذ & 0.085 & 0.085- & $=$ & 0.085 & - & 0 & $=$ & 0.845 & - & 1 & 3 \\
\hline
\end{tabular}

المصدر: من اعداد بالاعتماد على جدول (ء ().

تبين من خلال تحليل مؤشر ستوكاستيك أن سعر السهم لمصرف السلام-البحرين سوف يرتفع في المستقبل لذلك بمقدور المستثر شراء خيار شراء ، ويبين الجدول (10) ثلاثة سيناريوهات للتغير في سعر 
السهم لبيان حجم الأرباح والخسائر للمستثرين مشتري خيار البيع ومحرري خيار البيع (البائعين للخيارات

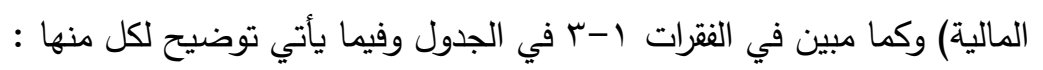

أ. تبين الفقرة المن الجدول (10) أن سعر السهم انخفض كما توقع المستثر فسوف يحقق أرباحاً

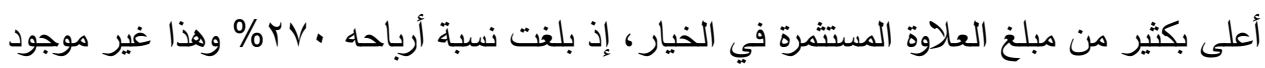

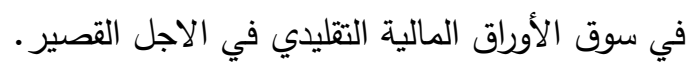

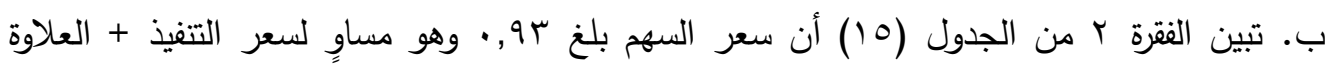

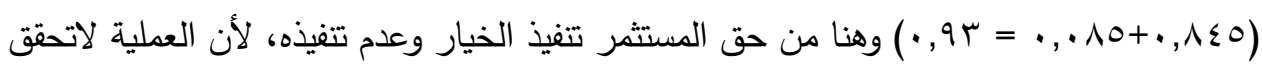
لله لاربحاً ولاخسارة (نقطة التعادل).

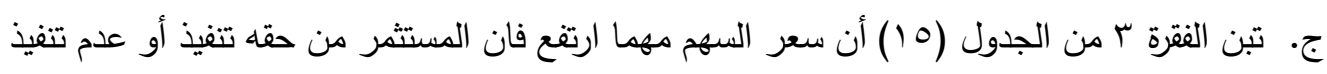

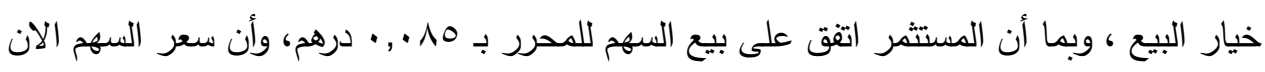

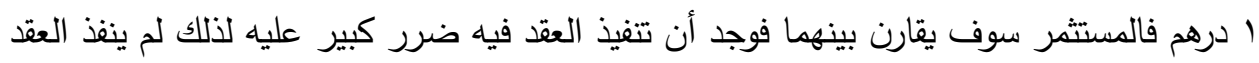

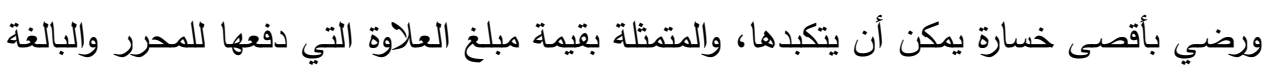

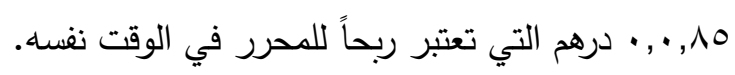

د. إذا كان المستثمر يستثمر في السوق التقليدي فانه يستطيع تسخير الخيارات المالية لتقليل الخسائر

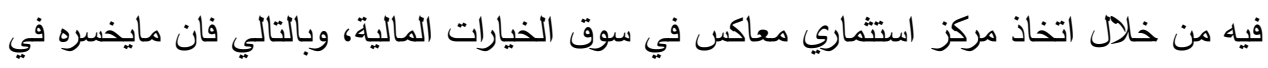
السوق التقليدي يكسبه في سوق الخيارات ما يقلل الخطر الذي يتعرض لـ له في المستقبل.

ثالثاً: الاستنتاجات وإلتوصيات

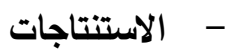

أ. يسهم مؤشر ستوكاستيك في مساعدة المستثرين في تحديد اتجاه السوق، وبالتالي التتبؤ في تغيرات

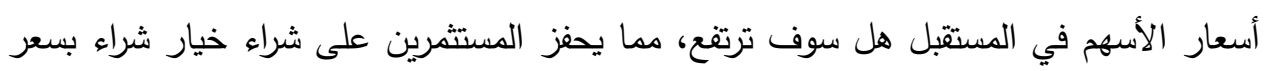

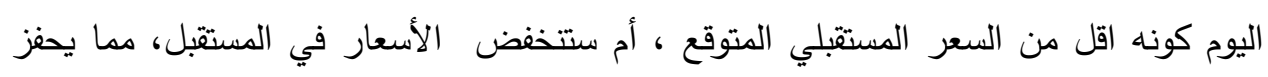
المستثرين على شراء خيار بيع بسعر اليوم، لأن سعر اليوم أعلى من السعر المستقبلي المتوقع.

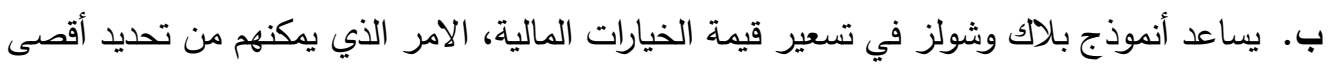

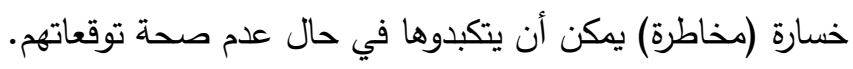
ج. يعلم المستثرون حجم الخسائر (المخاطرة) التي سوف يتكبدونها في حال عدم تحقق توقعاتهم بشأن تغير أسعار الأسهم في سوق الأوراق المالية التقليدي والمستقبلي والتي تتمثل بقيمة العلاوة المدفوعة للمحرري الخيارات المالية. د. تعد أرباح المستثرين غير محدودة كالخسائر، وانما كلما كان تغير سعر السهم في مصلحة المستثرين فإنهم سوف يقدمون على تتفيذ الخيارات المالية التي بحوزتهم، مما يعظم ثرواتهم وهذا هدف كافة المستثمرين. 
هـ. تساعد الأسواق المستقبلية المستثرين في الأسواق التقليدية في التحوط ضد الخسائر (المخاطر)

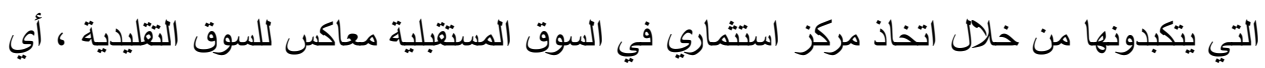

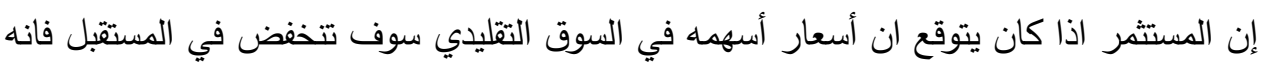

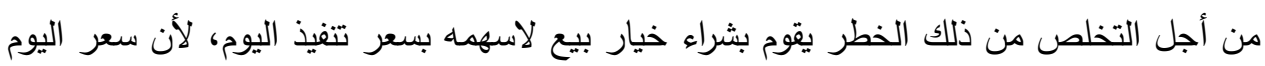

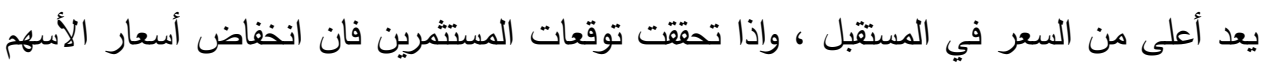
في السوق التقليدي يقابله بيعها في السوق المستقبلي بالسعر المتقق عليه قبل التغير، مما يبقي

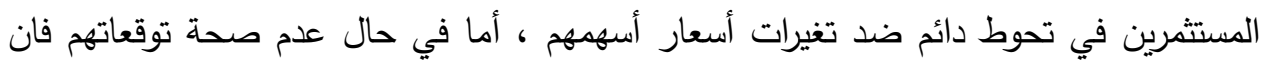
المستثمرين لن ينفذوا الخيارات التي بحوزتهم، وتكون خسائرهم محددة بقيمة العلاوة التي دفعوها

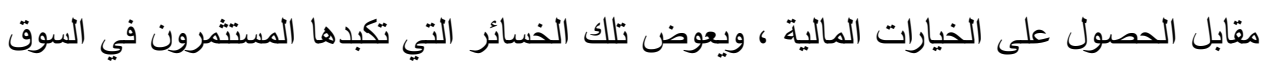
المستقبلي بارتفاع أسعار الأسهم في السوق التقليدي، مما يجلهم في حالة تحوط مستمرة من أخطار

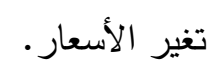
و. يحتاج الاستثمار في السوق التقليدي رأس مال أكبر بكثير من رأس المال المطلوب في السوق المستقبلي. ز. من النادر جداً أن يفوق حجم الأرباح في السوق التقليدي حجم رأس المال المستثر ، ولكن هذا الثيء اعتيادي في السوق المستقبلي.

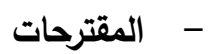

أ. نوصي المستثرين بالاستعانة بأحد مؤشرات تحديد اتجاه السوق والتي تساعدهم في تحديد الاتجاه المستقبلي للسوق. ب. نوصي المستثمرين باستخدام أنموذج بلاك وشولز في تسعير الخيارات المالية.

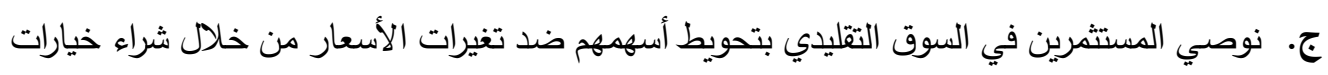
مالية عليها من السوق المستقبلي.

\section{References}

1. Reports and periodicals

a. The financial data published for the research sample in the Dubai Stock Exchange GFH Financial BSC.

\section{Dissertations \& Thesis}

a. Salam Salmiya, 2014, Financial Options Strategies in Building a Hedging Portfolio, A Kuwaiti Financial Market Case Study using a Model, Binomial, Black, sitoldis, Unpublished Master Thesis.

b. Kristopher Nhuyen, 2016, Atheists Submitted to the Fatuity of The University of Mississippi in Partial fulfillment of the requirement of the Sally, McDonnell Barksdale hours College.

c. B. Abdul Karim Rithmi, 2014, Options of Options Using a Binary Model and Building a Hedging Portfolio, Study of Petroleum Sector Money in the Kuwait 
Financial Market - During the 2012-2013 Period, Unpublished Master Thesis, Kassadi Murbah University - Ouargla - College of Economic, Commercial and Management Sciences with Sciences Managing.

d. C. Masouda bin Lakhdar, 2015, option contracts and their role in reducing risks, capital markets, an applied study on the Paris Stock Exchange for the period 20092014, unpublished master thesis, University of Mohamed Khader - Biskra - Faculty of Economic, Commercial and Management Sciences with economic sciences.

e. Dr. Boudiaf Abeer, 2007, Algeria Stock Exchange, unpublished doctoral dissertation, Mentouri University of Constantine, Algeria.

f. Al-Kindy, Hussein Hadi Abbas, 2019, Using options contracts to reduce risks, a study of a sample of companies listed on the Iraq Stock Exchange, unpublished Master Thesis, College of Administration and Economics, University of Qadisiyah.

g. And. Effat Muhammad Kamel Al-Nahal, 2017, Options Contracts as a Tool to Activate the Palestine Stock Exchange, Unpublished Master Thesis, Al-Azhar University, Gaza.

h. G. Sammour, Nabil Khalil Taha 2007, The Islamic Stock Market Between Theory and Practice (Case Study of the Islamic Capital Market in Malaysia), Unpublished Master Thesis, Islamic University, Gaza.

\section{Journal}

a. Shendi Adeeb Qassem, 2013, Financial Markets and Their Impact on Economic Development, Iraq Stock Exchange, Case Study, Baghdad College Journal of University Economic Sciences, Special Issue of the College Conference.

b. B. Al-Jubouri, Ali Aboudi Nehme, 2015, Employment of Advanced Financial Options Contracts to Build a Hedging Portfolio - An Empirical Study in the Iraqi Banking Sector, Babel Center Journal for Humanitarian Studies, Volume 5, No. 44.

c. C. Kandoul, Abdel Karim, 2015, the real options and their role in the financial evaluation of investment projects, Algerian Journal of Economic Development, No. 3, December 2015.

\section{4. book}

a. El-Hennawy, Mohamed Saleh, 2008, Analysis and Stock Bonding, University House, Alexandria, Egypt.

b. Al-Tamimi, Arshad Fouad, 2010, Financial Markets "A Framework in Regulating and Evaluating Tools", Al-Yazouri Scientific Publishing and Distribution House, Amman, Jordan.

c. Global finance program and Department of finance and ICMA center 2008, Saliln N. Neftci.

d. Principles of financial Engineering second Edition, printed in Canada.

e. Sanil parameswaran , 2011, fundamentals of financial instruments an introduction to stocks, Bonds, foreign exchange and Derivatives, Sohn Wileg \& Sons (Asia) pte. Ltd.

f. Roger G. Clarke, 2013, fundamentals of futures and options. CFA Institute. 


\section{Internet}

a. Mohamed Saadou Al-Jarf, 2016, Financial Options Contracts in Islamic Jurisprudence, Islamic Jurisprudence Forum, Second Cycle www.arab.iefpeia.com

b. Royal Class, 2006, Options Market for Research.www.info@ royalclassaed.com

c. Source: https://www.borsaat.com/stochastic-oscillator/

A. Dr. https://www.borsaat.com/stochastic-oscillator

B. Alexander Dejanovski , 2014 , the role and importance of the options as a unstandardized Financial Derivatives , TEM Journal, Volume3/Number1 www.temjournal.com .

C. Qi-wen wang, Jian-jun SHU., 2017 , Financial option Insurance , Risk management , Journal of risk crisis and disaster, Vol.19, No.1 .

D. Duc Hong Vo., \& etal , 2019, The importance of financial derivatives market major economies, Journal of risk and financial management, www.mdpir.com , Journal jrfm . 